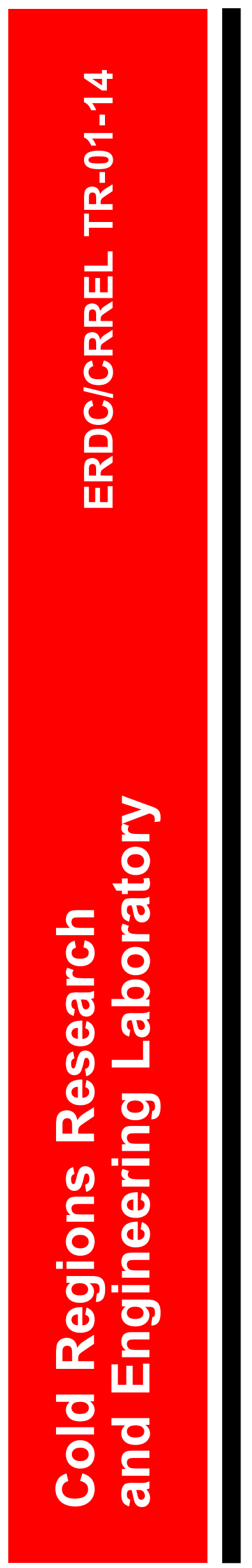

\title{
The Effect of Aggregate Angularity on Base Course Performance
}

US Army Corps of Engineers ${ }_{\circledast}$

Engineer Research and Development Center

Vincent C. Janoo and John J. Bayer II

September 2001 
Abstract: The Vermont Agency of Transportation (VAOT) conducted a two-phase study to quantify the resilient modulus and strength characteristics of its subbase material. In Phase 1, a literature review was done to determine the various methods available for indexing the shape, texture, and angularity of coarse aggregates. In the second phase, described in this report, a study was conducted to relate particle index to the mechanical resilient and shear properties of base course materials. The particle index as modified by the Michigan Department of Transportation used the complete gradation and was a good indicator of the crushed (angular) content of a given base course gradation. The particle index test also may be used to indicate resilient and shear properties of base course aggregate gradation.

\section{How to get copies of CRREL technical publications:}

Department of Defense personnel and contractors may order reports through the Defense Technical Information Center:

DTIC-BR SUITE 0944

8725 JOHN J KINGMAN RD

FT BELVOIR VA 22060-6218

Telephone (800) 225-3842

E-mail help@dtic.mil msorders@dtic.mil

WWW http://www.dtic.mil/

All others may order reports through the National Technical Information Service:

NTIS

5285 PORT ROYAL RD

SPRINGFIELD VA 22161

Telephone (703) 487-4650

(703) 487-4639 (TDD for the hearing-impaired)

E-mail_orders@ntis.fedworld.gov

WWW http://www.ntis.gov/index.html

A complete list of all CRREL technical publications is available from

USACRREL (CEERD-IM-HL)

72 LYME RD

HANOVER NH 03755-1290

Telephone (603) 646-4338

E-mail_erhoff@crrel.usace.army.mil

For information on all aspects of the Cold Regions Research and Engineering Laboratory, visit our

World Wide Web site:

http://www.crrel.usace.army.mil 


\section{Technical Report ERDC/CRREL TR-01-14}

\section{The Effect of Aggregate Angularity on Base Course Performance}

Vincent C. Janoo and John J. Bayer II 


\section{PREFACE}

This report was prepared by Dr. Vincent C. Janoo, Research Civil Engineer; and John J. Bayer II, Civil Engineering Technician, U.S. Army Engineer Research and Development Center (ERDC), Cold Regions Research and Engineering Laboratory (CRREL), Hanover, New Hampshire.

Funding for this report was provided by the Vermont Agency of Transportation (VAOT). This publication reflects the personal views of the authors and does not suggest or reflect the policy, practices, programs, or doctrine of the U.S. Army or Government of the United States. The contents of this report are not to be used for advertising or promotional purposes. Citation of brand names does not constitute an official endorsement or approval of the use of such commercial products. 


\section{CONTENTS}

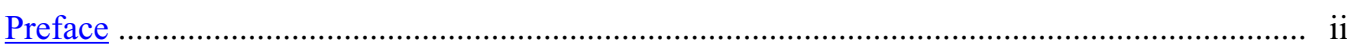

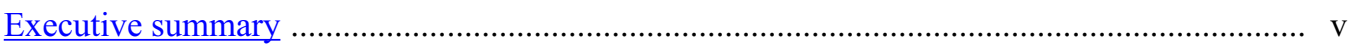

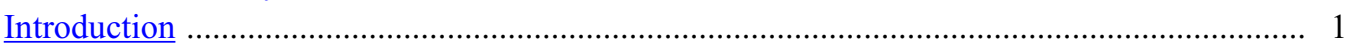

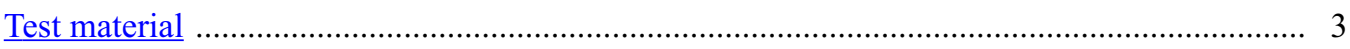

Moisture density

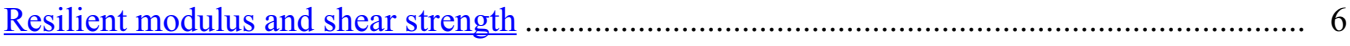

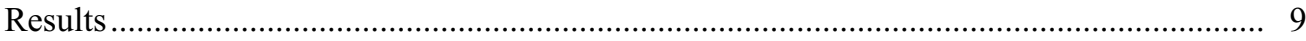

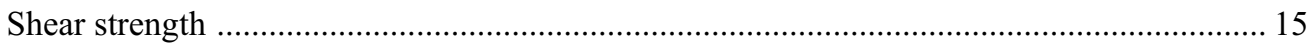

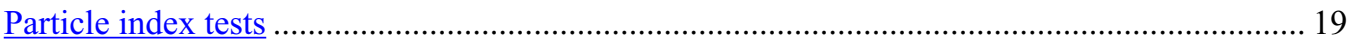

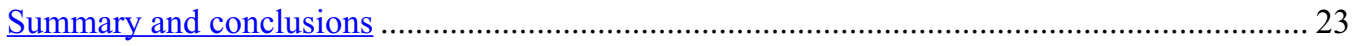

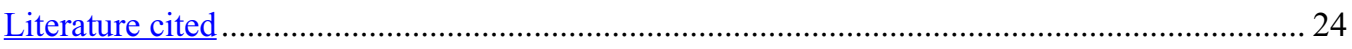

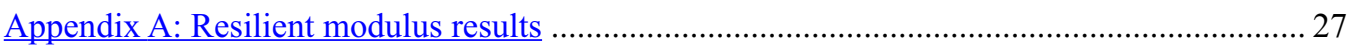

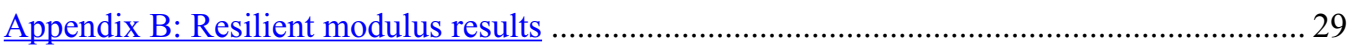

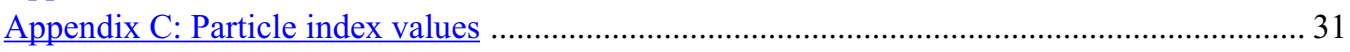

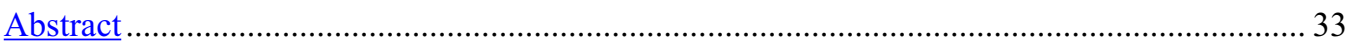

\section{ILLUSTRATIONS}

Figure

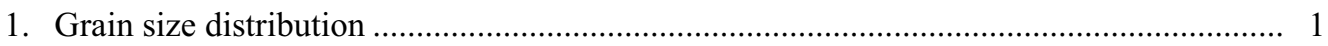

2. Resilient modulus as measured in 400-mm- and 150-mm-diameter specimens of coarse crushed masonry .............................................................................................. 2

3. Influence of material type and stress state on resilient modulus ..................................... 3

4. Gradation limits meeting VAOT subbase specification .................................................. 4

5. Gradation of subbase aggregate used in the AASHTO T-99 test ..................................... 5

6. Moisture density curves from T-99 and QMOT tests ..................................................... 5

7. QMOT test equipment for moisture density test ............................................................ 6

8. Relationship between dry densities from T-99 and QMOT for test aggregates ................. 6

9. Specimen preparation fo resilient modulus test …………………............................... 7

10. Test specimen prior to chamber placement ……...................................................... 8

11. Placement of triaxial chamber around test specimen …….......................................... 8

12. Applied stress measurement during resilient modulus test ............................................. 10

13. Corresponding strain measurement during resilient modulus test .................................. 10

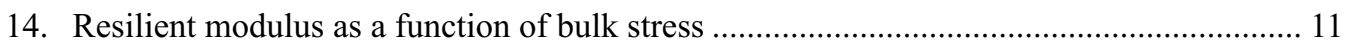

15. Resilient modulus as a function of bulk stress and aggregate angularity .......................... 13

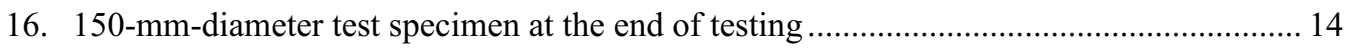

17. Resilient modulus as a function of bulk stress and aggregulate singularity ........................ 15

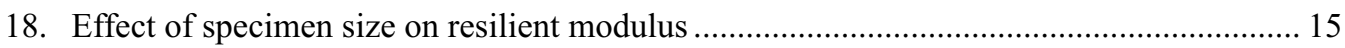

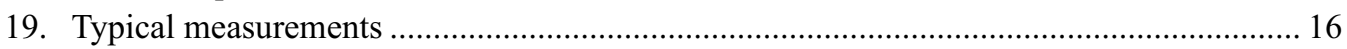


Figure

20. Mohr circles for $100 \%$ natural materials .................................................................. 17

21. Mohr circles for $25 \%$ natural materials ...................................................................... 17

22. Influence of void ratio on maximum shear stress ..................................................... 17

23. Effect of percent crushed aggregate, sample size, and void ratio on shear strength .......... 18

24. Effect of void ratio on the angle of internal friction ...................................................... 19

25. Particle index for different aggregate gradations ...................................................... 20

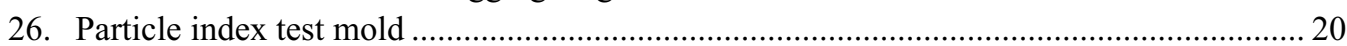

27. Void volume vs. particle index at compactive effort of 10 blows per layer...................... 21

28. Relationship between particle index and percent crushed aggregate in mixture .............. 21

29. Examples of angularities in test aggregate ................................................................... 22

30. Percentage of round, subround, angular, and subangular aggregates in particle index test

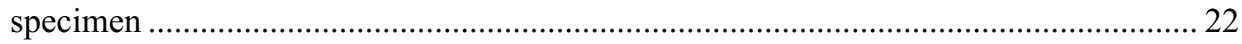

31. Effect of percentage of crushed aggregate on particle index .......................................... 23

32. Effect of particle index on resilient modulus ............................................................. 23

33. Angle of internal friction as a function of particle index ............................................ 24

\section{TABLES}

Table

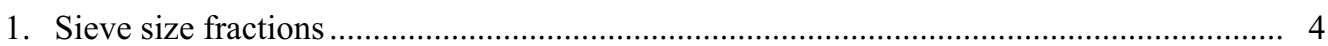

2. Aggregate specific gravity and absorption ................................................................. 4

3. Test sample proportions ..................................................................................... 4

4. Optimum moisture densities from AASHTO T-99 and QMOT tests .............................. 6

5. Modified testing sequence for VAOT base/subbase material ...................................... 9

6. Testing sequence for VAOT base/subbase material .................................................. 11

7. Test sample densities, moisture contents, and void ratios ................................................ 11

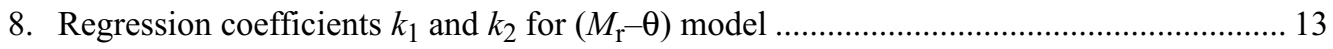

9. Test sample densities, moisture contents, and void ratios .............................................. 13

10. Average resilient modulus as a function of stress and angularity ................................... 14

11. Regression coefficients $k_{1}$ and $k_{2}$ for $\left(M_{\mathrm{r}}-\theta\right)$ model ............................................... 14

12. Shear strength material properties from large-scale tests ............................................ 16

13. Shear strength material properties from $150-\mathrm{mm}$ sample tests ....................................... 18

14. Shear strength as a function of percent crushed aggregates, void ratio, and specimen

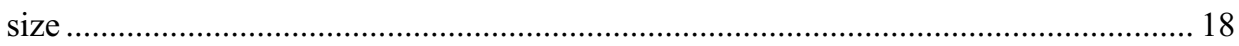

15. Average PI values for coarse and fine aggregates as a function of percent crushed aggregates 


\section{EXECUTIVE SUMMARY}

The Vermont Agency of Transportation (VAOT) attempted to quantify the resilient modulus and strength characteristics of its subbase material. Currently, VAOT defines the angularity of its base/subbase material by visual identification of the number of fractured faces, a method used by most state departments of transportation.

The study was conducted in two phases. In Phase 1, a literature review was done to determine the various methods available for quantifying or indexing the shape, texture, and angularity of coarse aggregates. (For the sake of brevity, "angularity" will include the particle shape, surface texture, and angularity of the aggregate, unless otherwise noted.) At the end of Phase 1, the particle index test was identified as VAOT's choice for quantifying the angularity of its base courses.

In the second phase, described in this report, a study was conducted to relate the particle index to the mechanical resilient and shear properties of base course materials. Resilient modulus and shear tests were conducted on base course aggregate gradation meeting VAOT base course specifications. It is well documented that the scalping of the larger stones and replacing with equivalent smaller aggregates changes the structure of the base course and in turn affects the resilient and shear properties. Tests were conducted on large-scale, 300-mm-diameter, 750-mm-height and standard 150-mm, 300-mm-height samples at ERDC/GSL in Vicksburg, Mississippi. In addition to the mechanical tests, a comparative study was conducted at the Quebec Ministry of Transportation (QMOT) on the effect of specimen size on the moisture density relationship. The tests were conducted in a 300-mm-diameter, 450-mm-height mold. The energy applied in the compaction process was similar to that applied on AASHTO-T99 Standard Proctor test samples. On the average, density was found to be about $12 \%$ higher from the large-scale QMOT tests than from the AASHTO T99 tests. The optimum moisture contents for both tests were approximately the same.

Results from the 300-mm-diameter resilient modulus tests indicated that resilient modulus is a function of the percentage of crushed aggregates and bulk stress. It was also found that, at lower bulk stress levels, the resilient modulus of the natural aggregate mixture was higher than the $100 \%$ crushed aggregate. The trend reversed when the bulk stress was greater than $300 \mathrm{kPa}$. This suggests that, at lower depths in a thick $(\geq 60 \mathrm{~cm})$ base course layer, the lower half of the base course can be constructed with natural material. Results also indicated that the void ratio affected the resilient modulus of aggregates containing $50 \%$ or less of crushed aggregates.

The resilient modulus of the $100 \%$ natural material was higher than the $100 \%$ crushed material for the standard 150-mm-diameter samples. We believe that the effect of the larger stones $(+19 \mathrm{~mm})$ significantly affected the resilient modulus, which was about 35 to $50 \%$ higher than that obtained from the large-scale tests.

Angle of internal frictions ranged between $31^{\circ}$ and $51^{\circ}$ for the large-scale shear tests. The effect of percent crushed material on the angle of internal friction was minimal at $50 \%$ and higher. However, there was a significant difference when the aggregate was $100 \%$ natural. The difference in the angle of internal friction was $20^{\circ}$.

The particle index as modified by the Michigan Department of Transportation used the complete gradation and was a good indicator of the crushed (angular) content of a given base course gradation. The particle index test appears to be a fair indicator of the resilient modulus. However, it may be used to indicate the shear properties of the base course aggregate gradation. 
To Contents 


\title{
The Effect of Aggregate Angularity on Base Course Performance
}

\author{
VINCENT C. JANOO AND JOHN J. BAYER II
}

\section{INTRODUCTION}

Base course performance in a pavement structure is dependent on its properties. In current mechanistic design procedures, this performance is tied to the elastic properties of resilient modulus and Poisson's ratio. Resilient modulus is affected by stress state, moisture content, temperature, plasticity index, density, and gradation. Details on the effects of the various factors can be found in state-of-the-art reports by Kolisoja (1997) and Lekarp (1999). The effect of stress state has been researched in depth and the resilient modulus of granular materials has been related to bulk and deviator (or octahedral) stresses (Brown and Pell 1967, Hicks and Monismith 1972, Uzan 1985). The following can be used to estimate resilient modulus as a function of stress state:

$$
\begin{aligned}
& M_{\mathrm{r}}=k_{1} \theta^{k_{2}} q^{k_{3}} \\
& M_{\mathrm{r}}=k_{1} \theta^{k_{2}} q^{k_{3}}
\end{aligned}
$$

where $M_{\mathrm{r}}=$ resilient modulus

$\theta=$ bulk stress (at maximum deviator stress)

$q=$ deviator stress

$k_{1}, k_{2}, k_{3}=$ material parameters (regression constants).

However, gradation, plasticity index, density, temperature, and moisture content also have an effect on the resilient modulus of base course materials. With respect to gradation, several factors affect the resilient modulus: fine content, gradation curve shape, and maximum aggregate size (Thom 1988). For example, referring to Figure 1, the stiffness of dry crushed limestone increased by 1.5 to 1.8 when the sand content (indexed by the value $n$ ) increased from $n=0.25$ to $n=$ 5.0. Sand content increases with decreasing values of $n$. Figure 1 can also be used to infer the effect of maximum size on resilient modulus. It can be surmised from Figure 1 that if resilient modulus increases with decreasing values of $n$, then resilient modulus decreases with increasing aggregate maximum size. Similar results were reported by Kolisoja (1997).

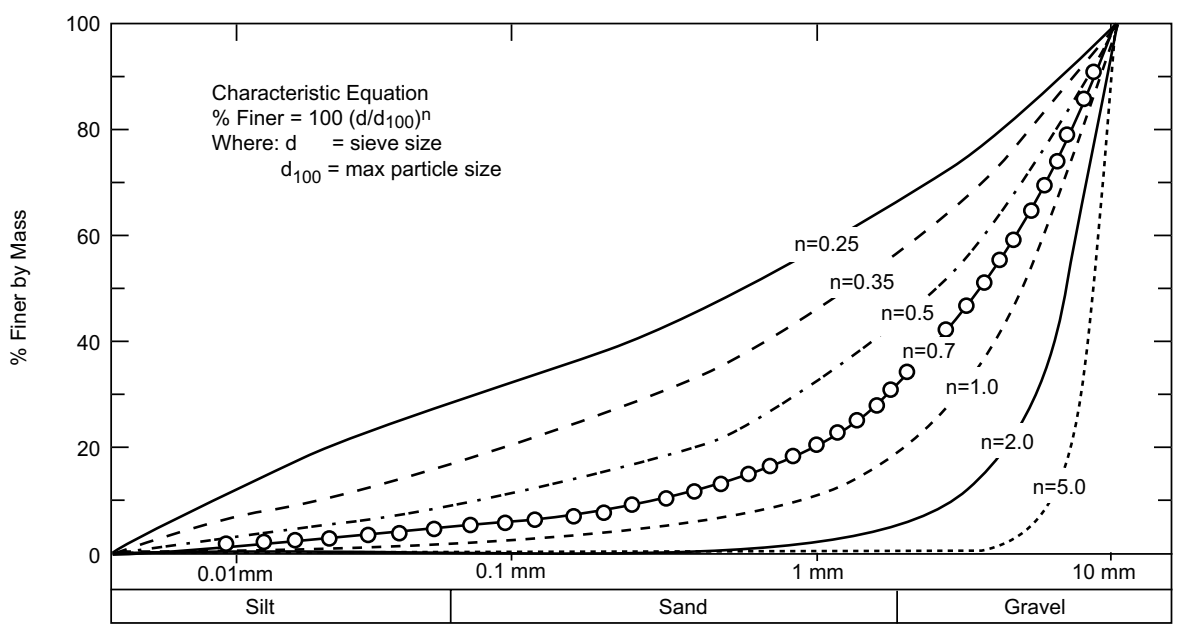

Figure 1. Grain size distribution. (After Thom 1988.) 


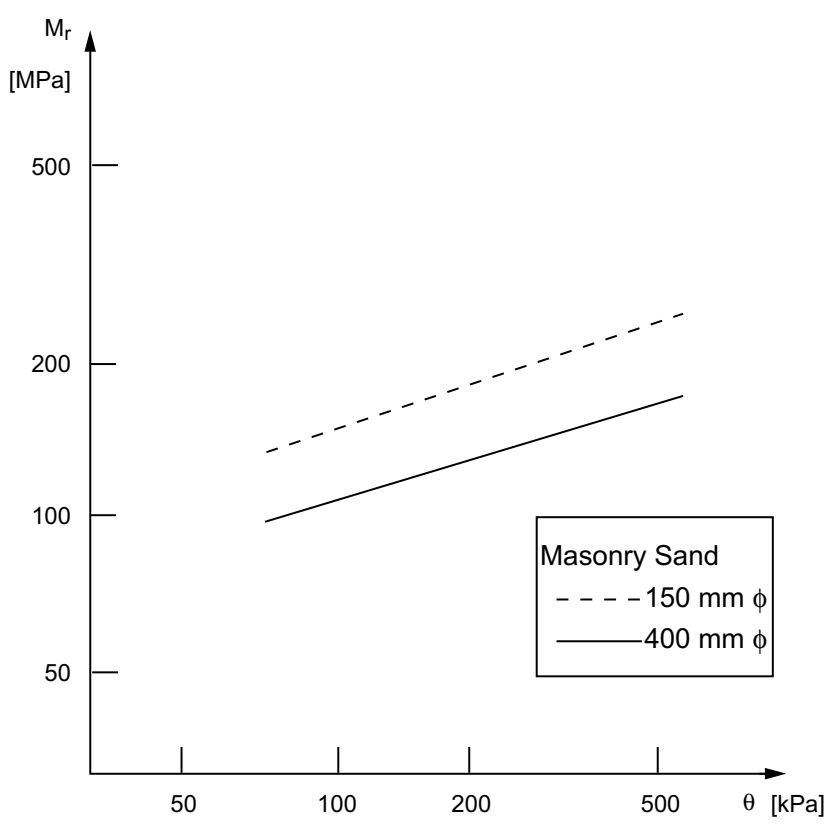

Figure 2. Resilient modulus as measured in 400-mmand $150-\mathrm{mm}$-diameter specimens of coarse crushed masonry. (After Sweere 1990.)

Most resilient modulus tests conducted on granular materials have been with aggregates not larger than 19 $\mathrm{mm}$. Sweere (1990) concluded from his study on unbound granular bases that specimen size does influence the measured resilient properties. He reported that the resilient modulus from large-scale (400-mm diameter) testing, can be about $70 \%$ of the standard 150 mm-diameter samples (Fig. 2). Specimen size is defined by maximum aggregate size. However, it has generally been recognized that with base course materials having a significant amount of large aggregates $(>25 \mathrm{~mm})$, scalping the aggregates to $19-\mathrm{mm}$ maximum size changes the gradation and thus the material properties. For base course materials, it is recommended that resilient modulus tests be conducted with specimens larger than $150 \mathrm{~mm}$.

The effect of density on resilient modulus seems to be dependent on material type. Kolisoja (1997) reviewed the literature and reported that some studies concluded that the effect of density on resilient modulus was insignificant (Thom 1988). Others, such as Hicks and Monismith (1971), Allen and Thompson (1974), and Rada and Witczak (1981) reported that in many cases the resilient modulus increased with density. The effect of moisture content on the resilient modulus of base course materials is through an interaction of the moisture content with the gradation and fines content. Initially, an increase in moisture content will increase the resilient modulus. As moisture content is further increased (increase in degree of saturation), the modulus will decrease. This is due to the lubrication effect of moisture on the fines in the base course mix. The higher the fine content, the more pronounced is the effect. Janoo (1997) reported that base course materials containing more than $3 \%$ fines were prone to thaw weakening (strength loss). Haynes and Yoder (1963) found that granular materials with a degree of saturation higher than $80 \%$ became unstable under repeated loading. Therefore, the base course design in cold regions is a compromise between density (fines content) and its permeability, since its strength is a function of its internal friction, which in turn is a function of its density, gradation, and particle shape (Yoder and Witczak 1975). Increase in density is usually obtained by increasing the fine content of the mix, which in turn may make it frost-susceptible.

Finally, data on the effect of aggregate shape, texture, and angularity on base course performance are limited. Shape, texture, and angularity can be quantified as specific measurements using petrological techniques or indexed as a lumped parameter, such as the angularity number, particle index (PI), etc. Details of both techniques can be found in Janoo (1998). Janoo cited two studies; one was on the effect of crushed base course material on creep strain and on the angle of internal friction (Holubec and Wilson 1970). The other was on base course material type (granite, gravel, and shale) on the resilient modulus (Barksdale and Itani 1994). The results were used to infer the effect of aggregate shape, texture, and angularity and are presented in Figure 3.

The Vermont Agency of Transportation (VAOT) is interested in determining the resilient modulus and strength characteristics of its subbase material. The focus is on the effect of the aggregate angularity on the resilient modulus. VAOT defines the angularity of its base/subbase material by visual identification of the number of fractured faces, a method commonly used by most state departments of transportation. The study was conducted in two phases. In Phase 1, a literature review was conducted on the various methods available for quantifying or indexing the shape, texture, and angularity of coarse aggregates. (For the sake of brevity, "angularity" will include particle shape, surface texture, and angularity of the aggregate, unless otherwise noted.) Also, any available laboratory or field test results were documented.

From Phase I, VAOT decided to use the PI as an indicator of the angularity of the base material. The PI $\left(I_{\mathrm{a}}\right)$ is calculated using the formula

$$
I_{\mathrm{a}}=1.25 V_{10}-0.25 V_{50}-32
$$

where $V_{10}=\%$ voids in aggregates at 10 strokes per layer and $V_{50}=\%$ voids in aggregates at 50 strokes per layer.

The PI test initially was developed for three differ- 


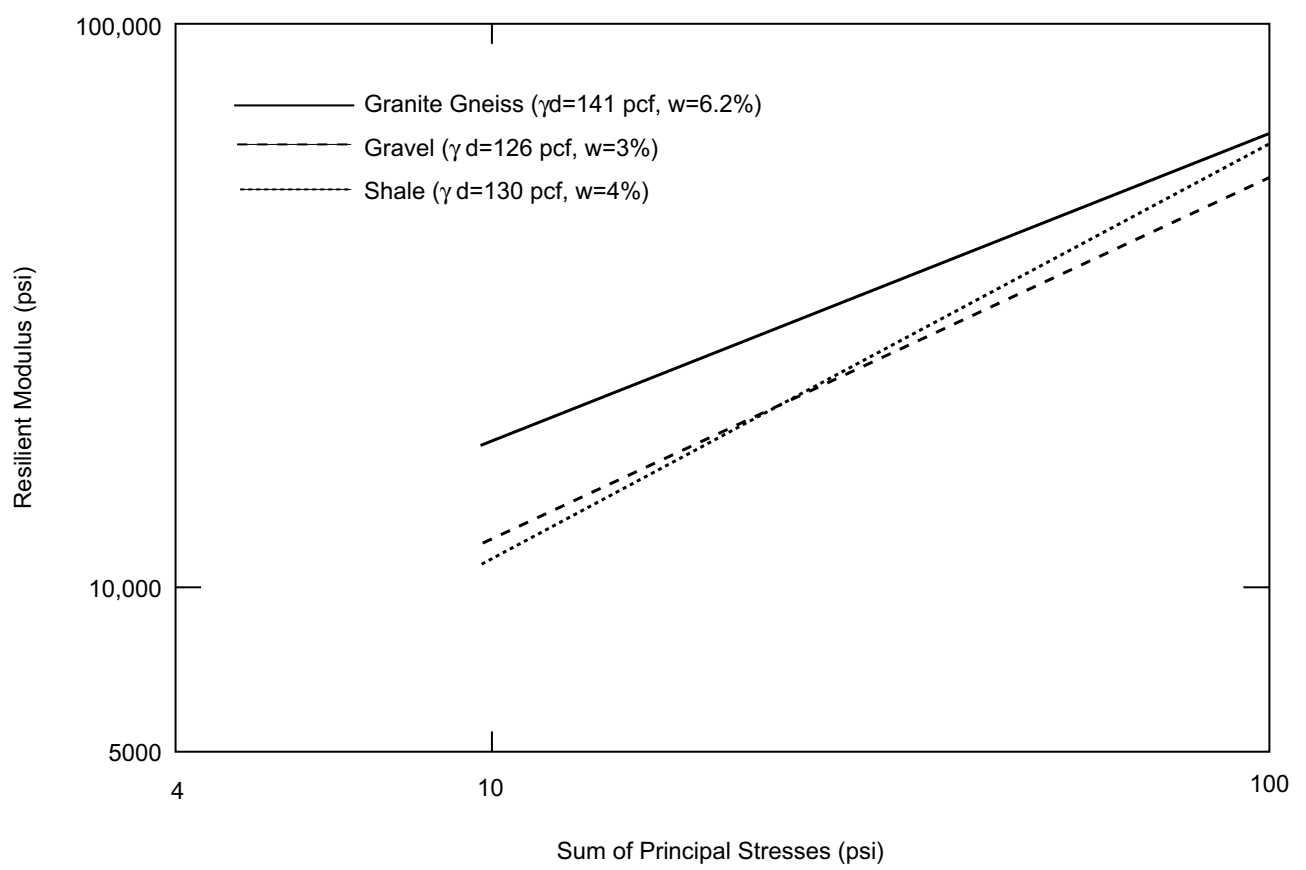

Figure 3. Influence of material type and stress state on resilient modulus. (After Barksdale and Itani 1994.)

ently sized aggregates: passing the $3 / 4$-in. and retained on the $1 / 2$-in. sieve; passing the $1 / 2$-in. and retained on the $3 / 8$-in. sieve; passing the $3 / 8$-in. and retained on the No. 4 sieve. For each size, the test involved tamping the uniform-sized aggregate into a mold in three equal layers using a standard tamping rod with 10 strokes per layer. The tamping rod was raised to a height of $50 \mathrm{~mm}$ from the top of the aggregate surface. At the end of the third layer, material was added to ensure that the aggregate surface was flush with the mold's rim. The test was repeated using 50 strokes and the percentage of void in the aggregate was calculated using the following equation:

$$
V_{\mathrm{n}}=\left[1-\frac{W_{\mathrm{n}}}{s * v}\right] 100
$$

where $V_{\mathrm{n}}=\%$ of voids at $n$ strokes per layer

$W_{\mathrm{n}}=$ net weight of aggregate in the mold at $n$ strokes per layer $(\mathrm{g})$

$s=$ bulk specific gravity of the aggregate

$v=$ volume of mold (cc).

Additional test details can be found in Huang (1965) or Janoo (1998).

In Phase II, several studies were conducted on base course materials containing $0,25,50,75$, and $100 \%$ crushed aggregates. Resilient modulus and shear strength tests were conducted on 300-mm-diameter and 762-mmheight samples. Prior to conducting these tests, another study was conducted to determine the moisture density relationship of the test material. Finally, PI tests were conducted to determine the index of the various aggregate materials.

\section{TEST MATERIAL}

Gravel samples were obtained from W.E. Dailey's crusher plant in South Shaftsbury, Vermont, for this research effort. The material consisted predominantly of quartz and quartzite with lesser amounts of carbonate rock types (limestone and dolomite). There was little to no micaceous rock in this gravel and, overall, the material was hard and durable and contained no deleterious substances.

The gravel was initially separated into each of the size fractions shown in Table 1 using a Gilson testing screen. All fractions were subsequently washed, ovendried, and allowed to cool. Aggregate particles larger than the No. 4 sieve were individually sorted into fractured (crushed) and naturally rounded groups.

Fractured aggregate was defined as particles having two or more freshly fractured faces; however, some particles with a single fracture were used to obtain the weights necessary for testing. Every attempt was made to use only aggregate pieces having sharp, well-defined edges in the "fractured" group. However, particles that may have been broken or fractured during trucking or handling, or through natural means resulting in subangular shapes, were grouped with the fractured 


\begin{tabular}{|cc|}
\hline $\begin{array}{l}\text { Table } \\
\text { tions. }\end{array}$ & \\
Passing & Retained \\
\hline 2 in. & 1 in. \\
1 in. & $3 / 4$ in. \\
$3 / 4$ in. & $2 / 3$ in. \\
$2 / 3$ in. & $3 / 8$ in. \\
$3 / 8$ in. & No. 4 \\
No. 4 & No. 8 \\
No. 8 & No. 16 \\
No. 16 & No. 30 \\
No. 30 & No. 50 \\
No. 50 & No. 100 \\
No. 100 & No. 200 \\
No. 200 & pan \\
\hline
\end{tabular}

material as well. Material placed in the "natural" category was generally rounded, although some subrounded particles were included. This part of the procedure was done manually and was independently spot-verified by a second party.

After both the crushed and natural materials were separated into each size fraction, the materials were combined to meet the test gradation shown in Figure 4. The test aggregate gradation was selected to fit near the center of the specification as shown. The test aggregate gradation had $100 \%$ passing $75 \mathrm{~mm}$ and $85 \%$ passing the $50-\mathrm{mm}$ sieve and classified as an A-1-a using the AASHTO classification or as GP or GP-GM using the Unified Soil Classification System. Aggregate samples were tested for specific gravity and absorption in accordance with AASHTO test methods T 84, Specific Gravity and Absorption of Fine Aggregate, and $\mathrm{T}$ 85, Specific Gravity and Absorption of Coarse
Aggregate. Test results for the natural and crushed products (material retained on the No. 4 sieve) and the fine fraction are presented in Table 2. The 136-kg samples having the proportions of crushed and natural material presented in Table 3 were placed in 189-L containers and delivered to CRREL.

\section{MOISTURE DENSITY}

Moisture density relationships were conducted by CRREL and VAOT. VAOT conducted the tests using AASHTO T-99 test method Moisture-Density Relations of Soils Using a 2.5-kg Rammer and a 305-mm DropMethod D. Aggregates larger than $19 \mathrm{~mm}$ were removed and replaced with an equal amount of material retained on the No. 4 sieve. A typical gradation curve for the aggregates used in the T-99 test is shown in Figure 5. For comparison, the actual gradation of the test aggregate is shown in the same figure. The T-99 test used a 152-mm-diameter mold; the sample was compacted in

\begin{tabular}{|c|c|c|}
\hline Material & $\begin{array}{c}\text { Absorption } \\
(\%)\end{array}$ & $\begin{array}{c}\text { Bulk specific } \\
\text { gravity }\end{array}$ \\
\hline Crushed gravel & 0.59 & 2.71 \\
\hline Natural gravel & 0.68 & 2.71 \\
\hline Minus No. 4 & 1.2 & 2.66 \\
\hline
\end{tabular}

\section{Table 3. Test sample proportions.}

\begin{tabular}{llllll}
\hline Crushed particles, \% & 100 & 75 & 50 & 25 & 0
\end{tabular}

Natural particles, \% $\quad \begin{array}{lllll}25 & 50 & 75 & 100\end{array}$

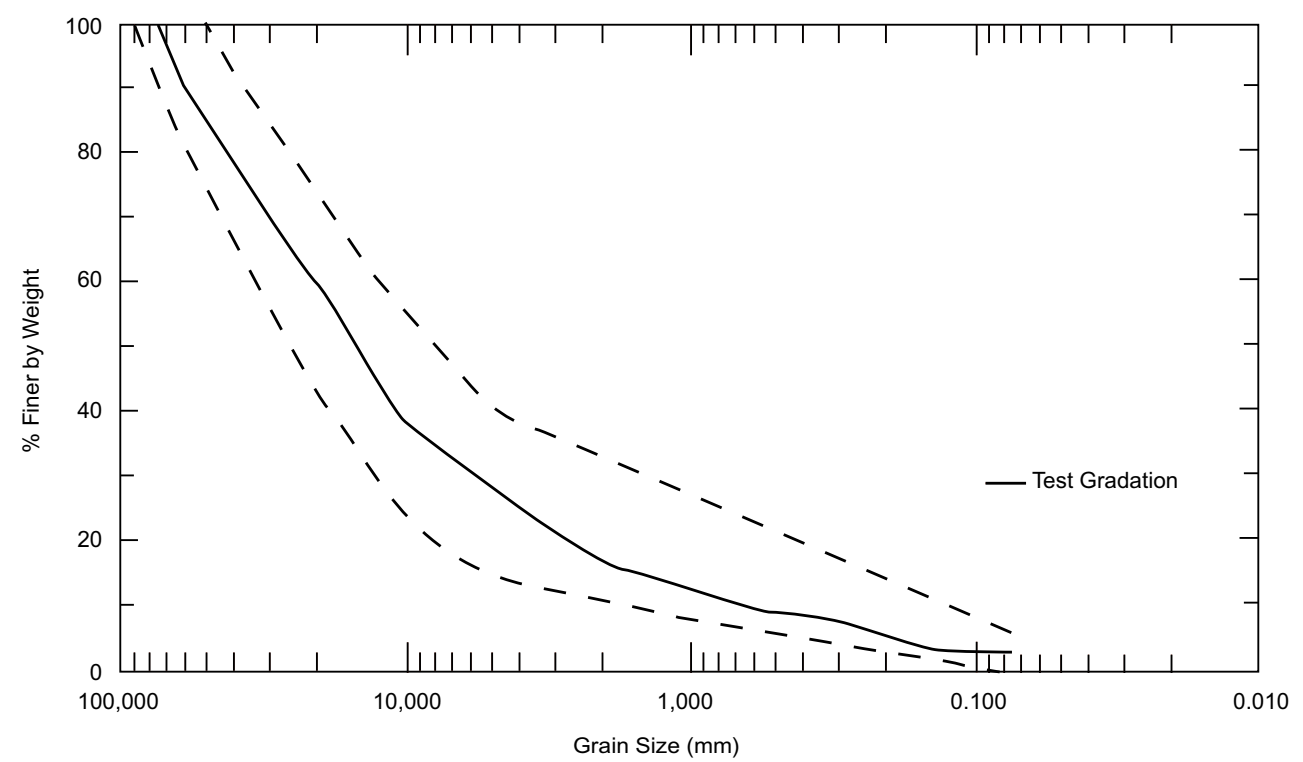

Figure 4. Gradation limits meeting VAOT subbase specification. 


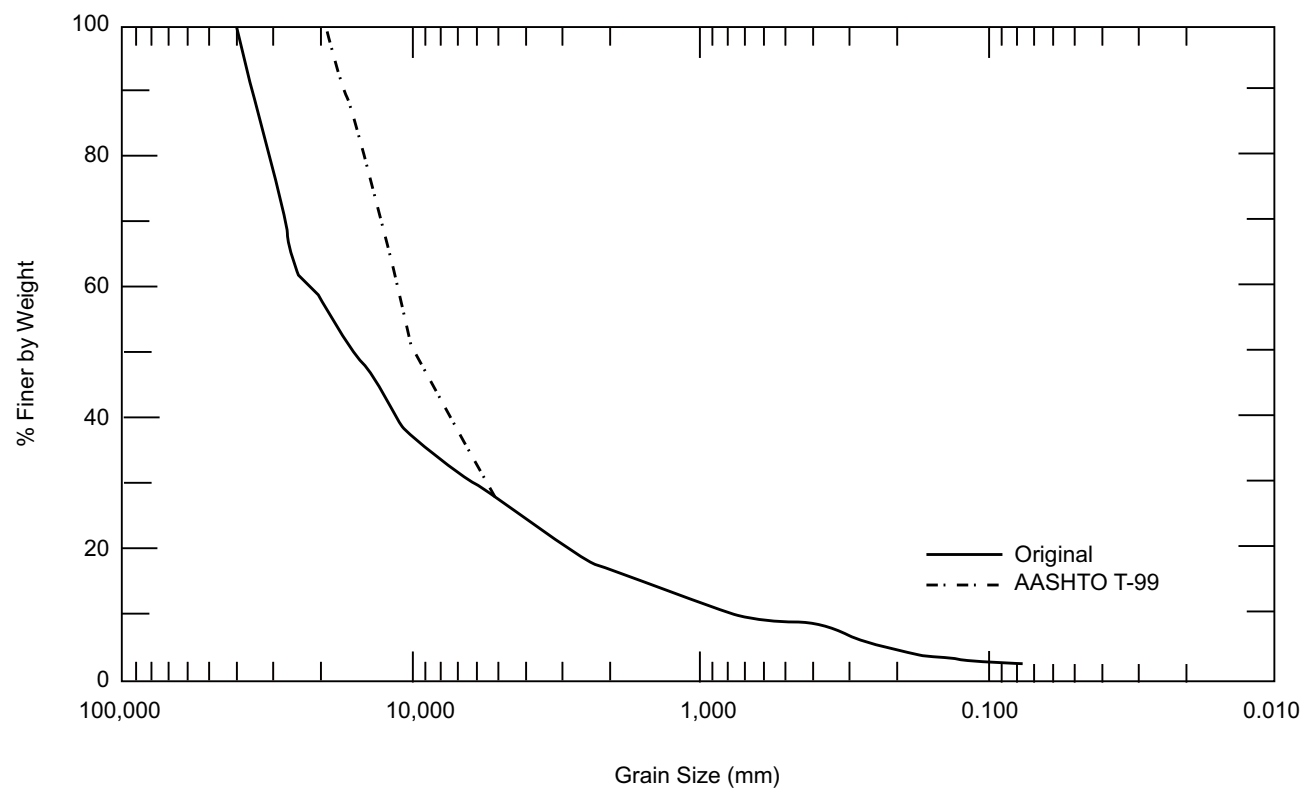

Figure 5. Gradation of subbase aggregate used in the AASHTO T-99 test.

five lifts and each lift was compacted with 56 rammer blows. Test results are presented in Figure 6.

A similar set of moisture density tests was conducted by CRREL using the test aggregate (Fig. 5) in a larger mold (300-mm diameter) at the Quebec Ministry of Transportation (QMOT) materials research laboratory in Quebec City (see Fig. 6). The test procedure was initially set up to simulate impact energy similar to that from the Modified Proctor Tests. For these tests, the procedure was modified to simulate the impact energy from the AASHTO T-99 test. The material was placed in three lifts and each lift was compacted with a $15-\mathrm{kg}$ rammer at a drop height of $450 \mathrm{~mm}$ (Fig. 7). The mold sat on a rotating base and rotated as the layer was compacted. Each layer was tamped 60 times. After the third layer, the material was leveled and weighed, collected in a tray, and weighed again. It was then dried in the oven overnight.

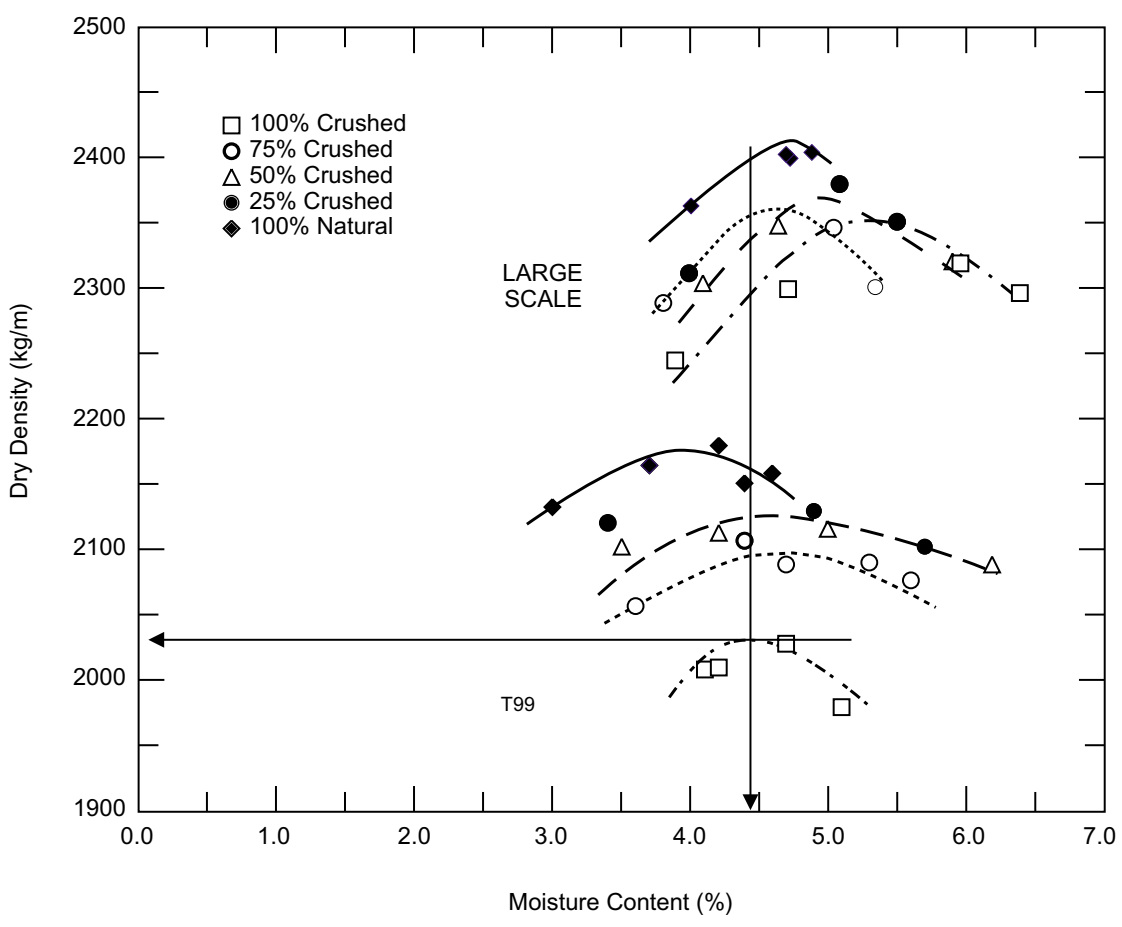

Figure 6. Moisture density curves from T-99 and QMOT tests. 


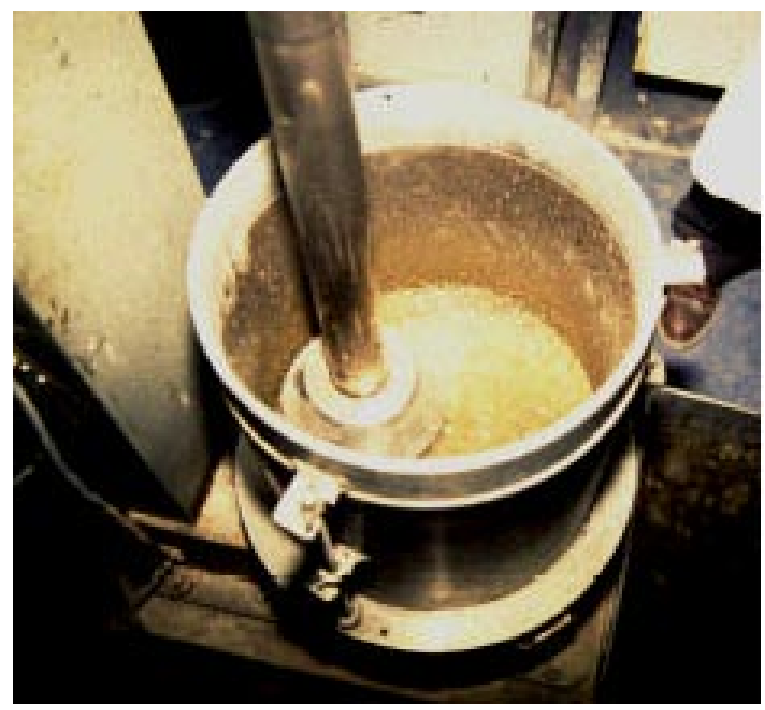

Figure 7. QMOT test equipment for moisture density test.

In both cases, the $100 \%$ crushed aggregates had a lower density than the $100 \%$ natural material and, as percent of natural aggregates in the mixture increased, so did the dry density. A comparison of the optimum moisture and dry density from both tests is presented in Table 4. The moisture contents are significantly different at the two ends of the spectrum (all natural and all crushed). At the other percentages, they are very similar. The density on the average is about $12 \%$ higher from the large-scale QMOT tests than from the AASHTO T-99 tests. The relationship between the large-scale and
Table 4. Optimum moisture densities from AASHTO T-99 and QMOT tests.

\begin{tabular}{lcccccc} 
& \multicolumn{2}{c}{ From T-99 } & & \multicolumn{2}{c}{ From QMOT } \\
\cline { 2 - 3 } Moisture & $\begin{array}{c}\text { Dry } \\
\text { content } \\
\text { Test material }\end{array}$ & & $\begin{array}{c}\text { Moisture } \\
\text { density } \\
\left(\mathrm{kg} / \mathrm{m}^{3}\right)\end{array}$ & & $\begin{array}{c}\text { Dontent } \\
(\%)\end{array}$ & $\begin{array}{c}\text { Density } \\
\left(\mathrm{kg} / \mathrm{m}^{3}\right)\end{array}$ \\
\hline 100\% Natural & 4.2 & 2180 & & 4.9 & 2404 \\
75N - 25C & 4.9 & 2129 & & 5.1 & 2381 \\
$50 \mathrm{~N}-50 \mathrm{C}$ & 4.8 & 2117 & & 4.6 & 2349 \\
25N - 75C & 5.1 & 2091 & & 5.0 & 2346 \\
100\% Crushed & 4.6 & 2028 & & 6.0 & 2319
\end{tabular}

T-99 densities is shown in Figure 8. Based on the test results, an estimate of the large-scaled density can be made from the T-99 test results from the following equation:

$$
\gamma_{\mathrm{d}}=0.57 \gamma_{\mathrm{d}_{\mathrm{T} 99}}+1163\left(\mathrm{~kg} / \mathrm{m}^{3}\right)(\text { see Fig. } 8) .
$$

\section{RESILIENT MODULUS AND SHEAR STRENGTH}

Resilient modulus and shear strength tests were conducted at the Corp of Engineers' Engineer Research and Development Center Geotechnical Structures Laboratory (ERDC/GSL) in Vicksburg, Mississippi. The blending of the natural to crushed ratios (100\% natural/ $0 \%$ crushed, $75 \%$ natural $/ 25 \%$ crushed, $50 \%$ natural $/$ $50 \%$ crushed, $25 \%$ natural $/ 75 \%$ crushed, and $0 \%$ natu$\mathrm{ral} / 100 \%$ crushed) were done by VAOT personnel and shipped in 189-liter drums. Prior to sample fabrication,

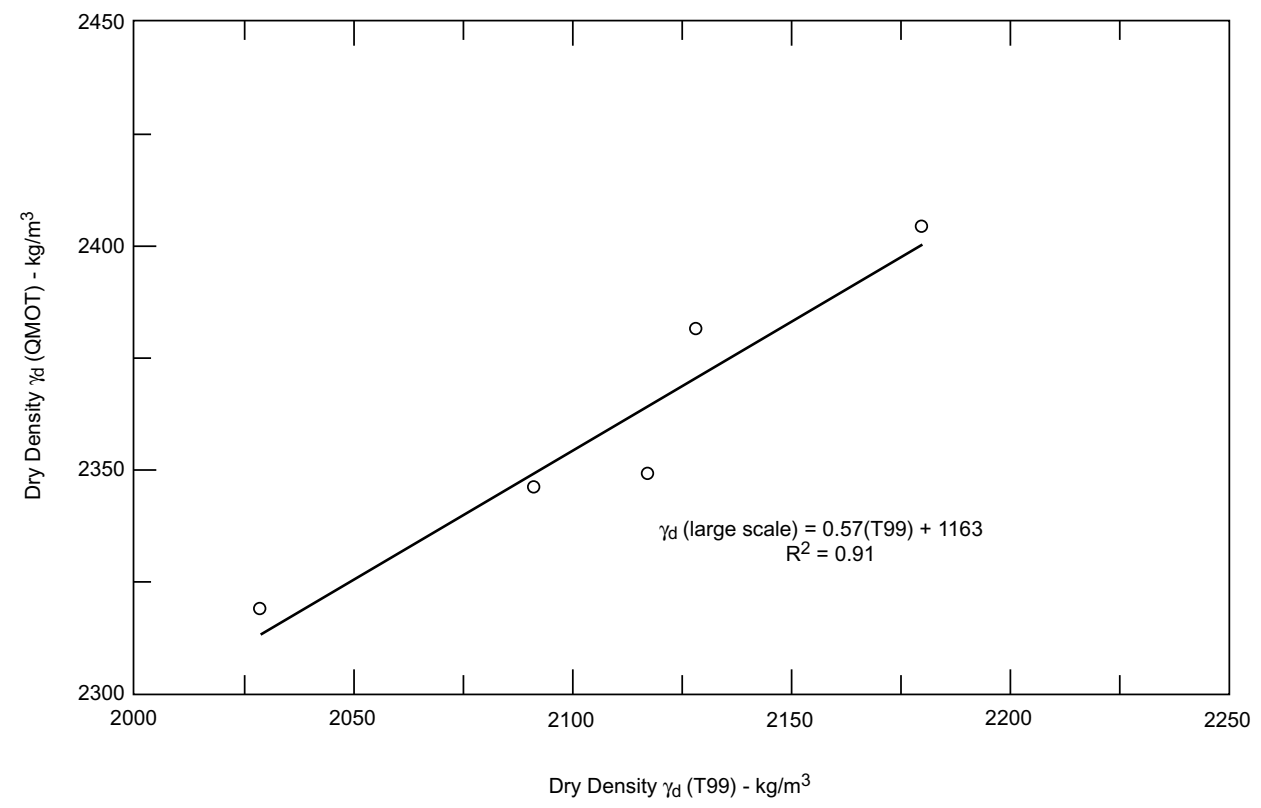

Figure 8. Relationship between dry densities from T-99 and QMOT for test aggregates. 
the test material was placed on the concrete floor in the laboratory to air-dry prior to obtaining a pretest sieve analysis. The material was turned regularly to expose fresh soil to the atmosphere to speed drying. When the soil had been air-dried sufficiently (as determined by the freshly turned soil's color and a representative water content test), the material was quartered and subdivided to obtain a representative sample that weighed about $9 \mathrm{~kg}$.

The representative sample was then passed through a nest of two sieves $(50 \mathrm{~mm}$ and $4.76 \mathrm{~mm})$. Soil that was retained or passed each sieve was placed in respective containers labeled as $+50 \mathrm{~mm},-50 \mathrm{~mm}$ to +4.76 $\mathrm{mm}$, and $-4.76 \mathrm{~mm}$. The weight of each container of soil was obtained (each container's tare weight had been previously obtained). The material in the container(s) identified as the $-50-\mathrm{mm}$ to $+4.76-\mathrm{mm}$ fraction was separated into fractions identified as $-50 \mathrm{~mm}$ to +38 $\mathrm{mm},-38 \mathrm{~mm}$ to $+25 \mathrm{~mm},-25 \mathrm{~mm}$ to $+19 \mathrm{~mm}$, $-19 \mathrm{~mm}$ to $+13 \mathrm{~mm},-13 \mathrm{~mm}$ to $+10 \mathrm{~mm},-10 \mathrm{~mm}$ to $+6.35 \mathrm{~mm},-6.35 \mathrm{~mm}$ to $+4.76 \mathrm{~mm}$, and $-4.76 \mathrm{~mm}$ by sieving on a mechanical sieve shaker. The weights of each fraction were obtained. The $-4.76-\mathrm{mm}$ fraction from the mechanical-sieving operation was combined with the $-4.76-\mathrm{mm}$ fraction from the hand-sieving operation. The air-dried weight and the water content of a representative sample of the combined $-4.76-\mathrm{mm}$ fraction were obtained. A representative sample of the combined -4.76-mm fraction was obtained using the "quartering" method to subdivide the material to a sample of a few hundred grams required for the sieve analysis. The sieve analysis of the representative sample of the $-4.76-\mathrm{mm}$ fraction was then conducted. The results of the sieve analyses obtained on the $-50-\mathrm{mm}$ to $+4.76-\mathrm{mm}$ fraction and the $-4.76-\mathrm{mm}$ fraction were used to obtain the representative gradation of the material received.

Resilient modulus tests were conducted in a triaxial apparatus equipped with a closed-loop hydraulic system on specimens molded using each of the material types. The nominal dimensions of the triaxial specimens were $300-\mathrm{mm}$ diameter by $750-\mathrm{mm}$ height. The target densities varied between 2323 and $2403 \mathrm{~kg} / \mathrm{m}^{3}$. The weight of dry aggregate required to mold each specimen was on the order of $136 \mathrm{~kg}$, depending on the target density for the respective specimens. All specimens were molded using twelve equal (air-dry) weight (and compacted thickness) lifts of soil. Sufficient water was mixed with the air-dried soil to increase the water content of each lift to the required water content for each material type. After each lift was placed in the mold, a hand-held rammer was used to compact the soil to a specified thickness (distance from the top of the mold) (Fig. 9).

When the specimen had been molded, the mold containing the compacted specimen was placed on the base of the triaxial chamber and a vacuum of about $34.5 \mathrm{kPa}$ was applied to the specimen. Once the vacuum within the specimen had stabilized, i.e., it was determined that the membrane was not leaking, the mold was removed from the specimen and the dimensions of the membraneencapsulated specimen were obtained. A second latex membrane was then placed over the specimen prior to assembling the triaxial chamber (Fig. 10).

The triaxial chamber was assembled (Fig. 11), the closed loop hydraulic system was activated, and the (axial) load cell was attached to the specimen top platen. Initial instrumentation readings, i.e., chamber pressure, pore pressure, axial load, axial deformation using the "closed-loop" LVDT and the "specimen" LVDT, were recorded. For all tests, the axial (overall) deformation of the specimen was measured using an LVDT with a resolution and linearity on the order of $\pm 10 \mu \mathrm{m}$. The resolution and linearity of the chamber pressure and the pore pressure transducers were about $\pm 2 \mathrm{kPa}$.

For the first series of resilient modulus tests, a 45$\mathrm{kN}$ load cell was used. For the second series, a highercapacity $(89 \mathrm{~N})$ load cell was selected. Note that all instrumentation was zeroed prior to placing the compacted specimen on the base of the triaxial apparatus. After the chamber was assembled and instrumentation readings were obtained, the vacuum that had been applied to the specimen through the pore pressure system was gradually reduced as chamber pressure was simultaneously increased. After the vacuum had been reduced to atmospheric pressure, chamber pressure was increased to $103 \mathrm{kPa}$ prior to initiating the resilient modulus test.

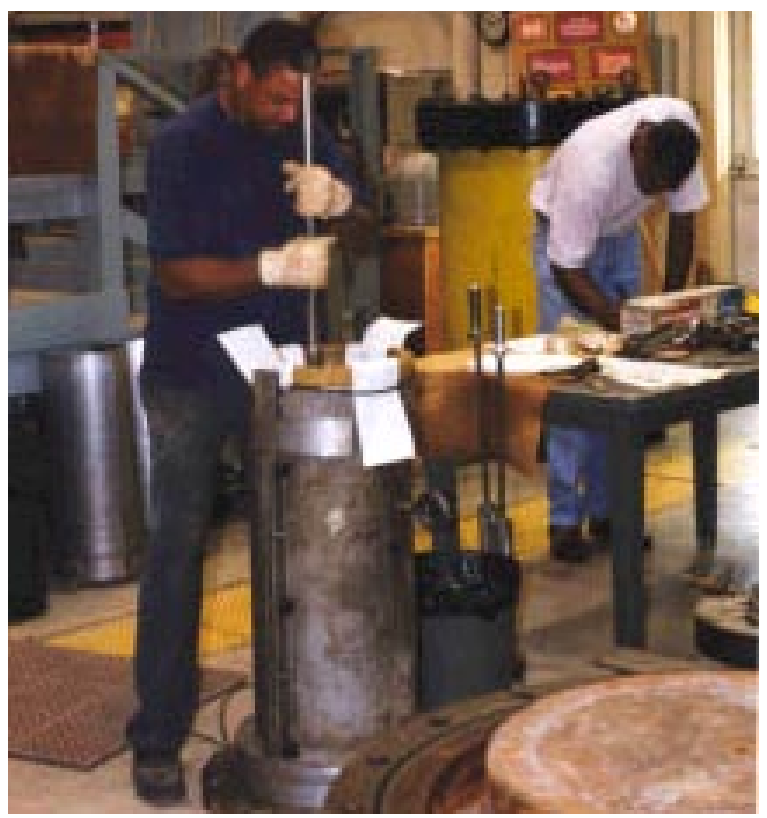

Figure 9. Specimen preparation for resilient modulus test. 


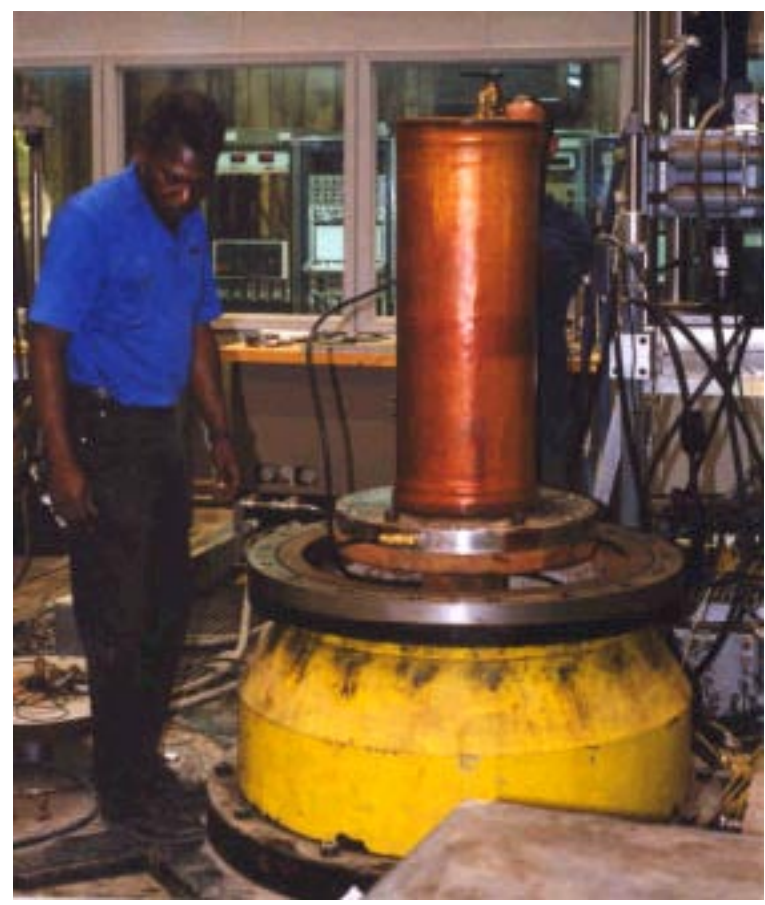

Figure 10. Test specimen prior to chamber placement.

In general, the testing procedures followed AASHTO Designation TP46-94, "Standard Test Method for Determining the Resilient Modulus of Soils and Aggregate Materials: Table 2. Testing Sequences for Base/Subbase Materials." Three modifications should be noted, however. First, the top and bottom platens of the triaxial apparatus were rigidly connected to the hydraulic actuator and the load cell using threaded rods. Second, the $21-\mathrm{kPa}$ confining pressure phase of the resilient modulus test was not conducted because of concern that the cyclic load plus the "overburden" weight of soil above the bottommost portion of the specimen could cause failure of the specimen during the resilient modulus test. Third, the $34.5-\mathrm{kPa}$ confining pressure phase of the resilient modulus test was conducted following the $138-\mathrm{kPa}$ confining pressure phase. Again, there was concern that a failure could occur during the $34.5-\mathrm{kPa}$ resilient modulus test. The modified testing sequence used for the test program is shown in Table 5.

Each resilient modulus loading phase consisted of applying a cyclic (deviator) stress (a haversine wave) for a duration of $0.1 \mathrm{~s}$ followed by a rest period of $0.9 \mathrm{~s}$, during which a contact stress was maintained on the specimen. For each loading history, the contact stress was 10 percent of the maximum axial (deviator) stress and the cyclic stress was 90 percent of the maximum axial stress. The first phase of the resilient modulus test consisted of the conditioning phase. During this phase, 1000 cycles of load (a contact deviator stress of $10 \mathrm{kPa}$ plus a cyclic deviator stress of $93 \mathrm{kPa}$ ) was applied to

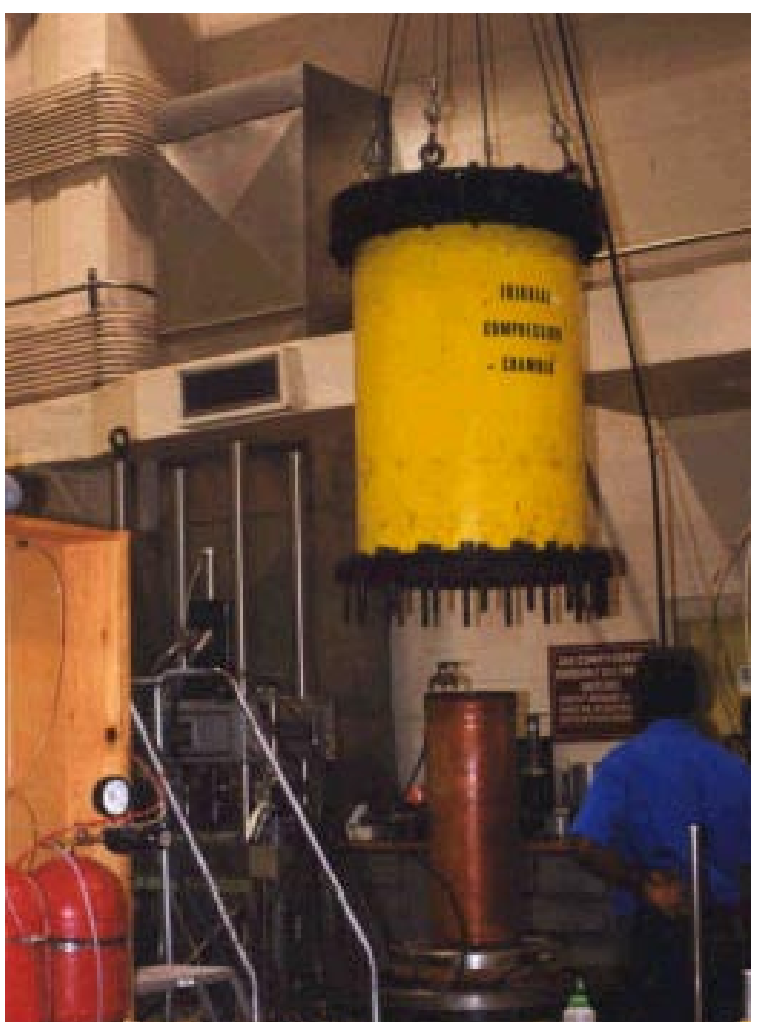

Figure 11. Placement of triaxial chamber around test specimen.

the sample. A real-time analysis of the data was conducted (a computer-generated plot of axial deformation versus the square root of time was obtained) as the data were recorded to ensure that an asymptotic state was obtained due to the applied loading history.

After the conditioning phase was completed, three axial loading histories each for confining pressures of $69 \mathrm{kPa}, 103 \mathrm{kPa}$, and $138 \mathrm{kPa}$ were conducted. At the end of each history, which consisted of 100 cycles of axial load, the rebound response of each specimen was monitored and recorded for five minutes. Upon completion of resilient modulus test phases, chamber pressure was reduced to $34.5 \mathrm{kPa}$. At the conclusion of the resilient modulus test, a deformation- (or displacement-) ratecontrolled shear test was conducted. Strain rate was about $1 \%$ per minute. For the initial series of resilient modulus tests, the confining pressure during the shear phase was $34.5 \mathrm{kPa}$. For the replicate series of tests, confining pressure during the shear phase was $69 \mathrm{kPa}$.

Following the completion of each test, the specimen was removed from the triaxial chamber and dried in an oven at $110^{\circ} \mathrm{C}$ to obtain the post-test water content and dry weight of soil. After these data were obtained, a posttest sieve analysis was conducted on each specimen following the procedures described earlier.

A similar series of tests was conducted on a $150-\mathrm{mm}$ diameter and 300-mm-height sample. However, material 


\begin{tabular}{|c|c|c|c|c|c|}
\hline $\begin{array}{c}\text { Sequence } \\
\text { no. }\end{array}$ & $\begin{array}{c}\text { Confining } \\
\text { pressure } \\
(\mathrm{kPa})\end{array}$ & $\begin{array}{c}\text { Maximum } \\
\text { axial stress } \\
(\mathrm{kPa})\end{array}$ & $\begin{array}{l}\text { Cyclic } \\
\text { stress } \\
(\mathrm{kPa})\end{array}$ & $\begin{array}{c}\text { Contact } \\
\text { stress } \\
(\mathrm{kPa})\end{array}$ & $\begin{array}{c}\text { Number of } \\
\text { load } \\
\text { applications }\end{array}$ \\
\hline 0 & 103.4 & 103.4 & 93.1 & 10.3 & $500-1000$ \\
\hline 1 & 68.9 & 68.9 & 62.0 & 6.9 & 100 \\
\hline 2 & 68.9 & 137.9 & 124.1 & 13.8 & 100 \\
\hline 3 & 68.9 & 206.8 & 186.1 & 20.7 & 100 \\
\hline 4 & 103.4 & 68.9 & 52.0 & 6.9 & 100 \\
\hline 5 & 103.4 & 103.4 & 93.1 & 10.3 & 100 \\
\hline 6 & 103.4 & 206.8 & 186.1 & 20.7 & 100 \\
\hline 7 & 137.9 & 103.4 & 93.1 & 10.3 & 100 \\
\hline 8 & 137.9 & 137.9 & 124.1 & 13.8 & 100 \\
\hline 9 & 137.9 & 275.8 & 248.2 & 27.6 & 100 \\
\hline 10 & 34.5 & 34.5 & 31.0 & 3.5 & 100 \\
\hline 11 & 34.5 & 68.9 & 62.0 & 6.9 & 100 \\
\hline 12 & 34.5 & 103.4 & 93.1 & 10.3 & 100 \\
\hline
\end{tabular}

larger than $19 \mathrm{~mm}$ was removed and replaced with an equal amount of material passing the $19-\mathrm{mm}$ sieve and retained on the $4.75-\mathrm{mm}$ sieve. The sample was prepared in $150-\mathrm{mm}$ lifts at the prescribed moisture content and compacted in accordance with AASHTO TP-46. The testing sequence was as prescribed in Table 2 of AASHTO TP-46 and is reproduced here as Table 6. The sample conditioning, data acquisition, and post testing were similar to the large-scale samples.

\section{Results}

The resilient modulus is defined as

$$
M_{\mathrm{r}}=\frac{\sigma_{\mathrm{d}}}{\varepsilon_{\mathrm{r}}}
$$

where $M_{\mathrm{r}}=$ resilient modulus

$$
\sigma_{\mathrm{d}}=\text { deviator stress }
$$$$
\varepsilon_{\mathrm{r}}=\text { resilient strain }
$$

The resilient modulus was determined as an average of the last five measurements of the deviator stress and resilient strains as shown in Figures 12 and 13. In addition to dry density and moisture content, the void ratio $(e)$ was calculated for each test specimen prior to testing, as follows:

$$
e=\frac{V_{\mathrm{V}}}{V_{\mathrm{s}}}
$$

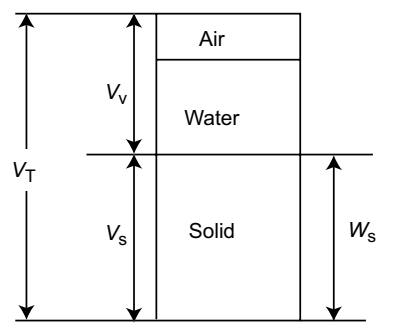

where $V_{\mathrm{v}}=$ volume of voids and $V_{\mathrm{s}}=$ volume of solids.

$V_{\mathrm{S}}$ is determined by the following expression:

$$
V_{\mathrm{s}}=\frac{W_{\mathrm{s}}}{G_{\mathrm{s}} \gamma_{\mathrm{w}}}
$$

where $W_{\mathrm{s}}=$ weight of solids (dry weight of sample)

$\gamma_{\mathrm{w}}=$ density of water

$G_{\mathrm{S}}=$ specific gravity of solids (aggregate mixture).

The void ratio $(e)$ can be rewritten as

$$
\begin{gathered}
e=\frac{V_{\mathrm{v}}}{\frac{W_{\mathrm{s}}}{G_{\mathrm{s}} \gamma_{\mathrm{w}}}}=\frac{V_{\mathrm{t}}-\frac{W_{\mathrm{s}}}{G_{\mathrm{s}} \gamma_{\mathrm{w}}}}{\frac{W_{\mathrm{s}}}{G_{\mathrm{s}} \gamma_{\mathrm{w}}}}=\frac{\frac{W_{\mathrm{s}}}{\gamma_{\mathrm{d}}}-\frac{W_{\mathrm{s}}}{G_{\mathrm{s}} \gamma_{\mathrm{w}}}}{\frac{W_{\mathrm{s}}}{G_{\mathrm{s}} \gamma_{\mathrm{w}}}} \\
=\frac{\frac{W_{\mathrm{s}}}{\gamma_{\mathrm{d}}}-\frac{W_{\mathrm{s}}}{\mathrm{G}_{\mathrm{s}} \gamma_{\mathrm{w}}}}{\frac{W_{\mathrm{s}}}{\mathrm{G}_{\mathrm{s}} \gamma_{\mathrm{w}}}}=\frac{\frac{1}{\gamma_{\mathrm{d}}}-\frac{1}{\frac{1}{\mathrm{G}_{\mathrm{s}} \gamma_{\mathrm{w}}}}}{\frac{1}{\mathrm{G}_{\mathrm{s}} \gamma_{\mathrm{w}}}}
\end{gathered}
$$

where $V_{\mathrm{t}}=$ total volume and $\gamma_{\mathrm{d}}=$ dry density.

The optimum and test densities, void ratios, and target moisture contents for the test samples are presented in Table 7. Relative densities ranged from 0.95 to 1.05 , with most around 0.98 . This provided an opportunity to quantify the effect of density on the resilient and shear properties. Target moisture contents ranged from 4.6 to $5.4 \%$. At the end of the test, some standing water was found at the bottom of some of the test samples.

Average resilient modulus results from the individual tests are presented in Appendix A. In a triaxial test, bulk stress or the first stress invariant $(\theta)$ is defined as

$$
\begin{aligned}
\theta & =\sigma_{1}+2 \sigma_{3} \\
& =\sigma_{d}+3 \sigma_{3}
\end{aligned}
$$




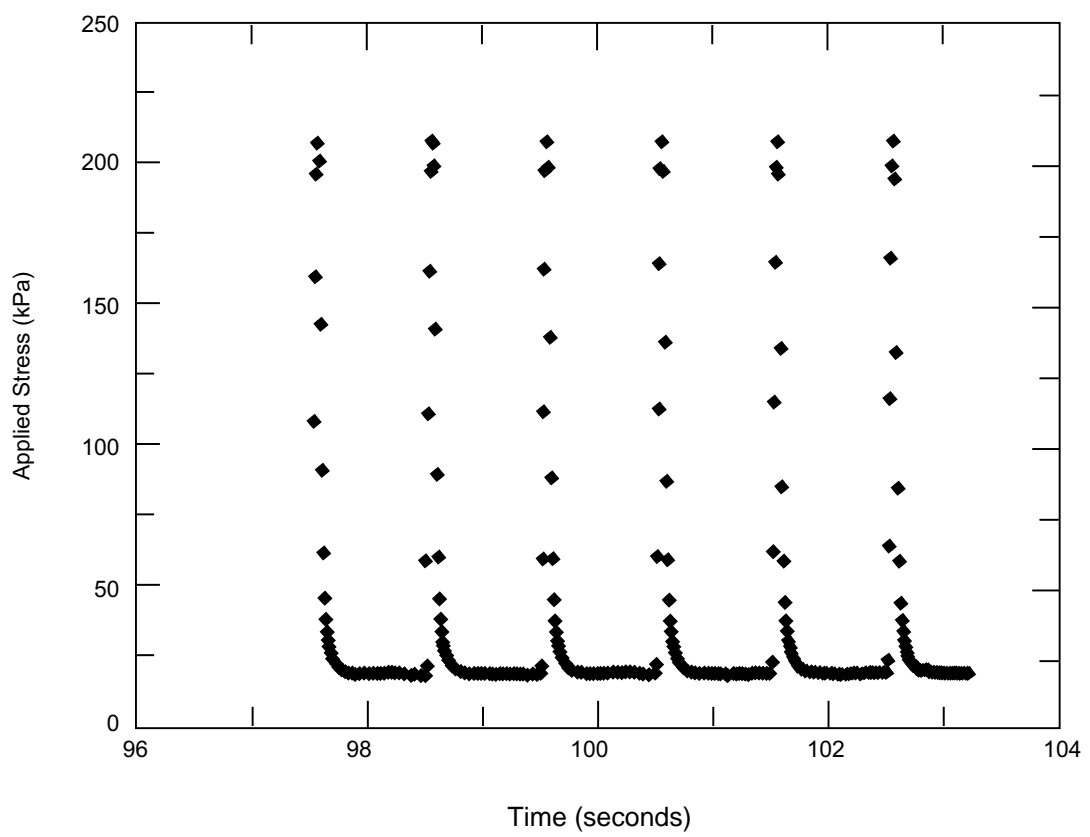

Figure 12. Applied stress measurement during resilient modulus test.

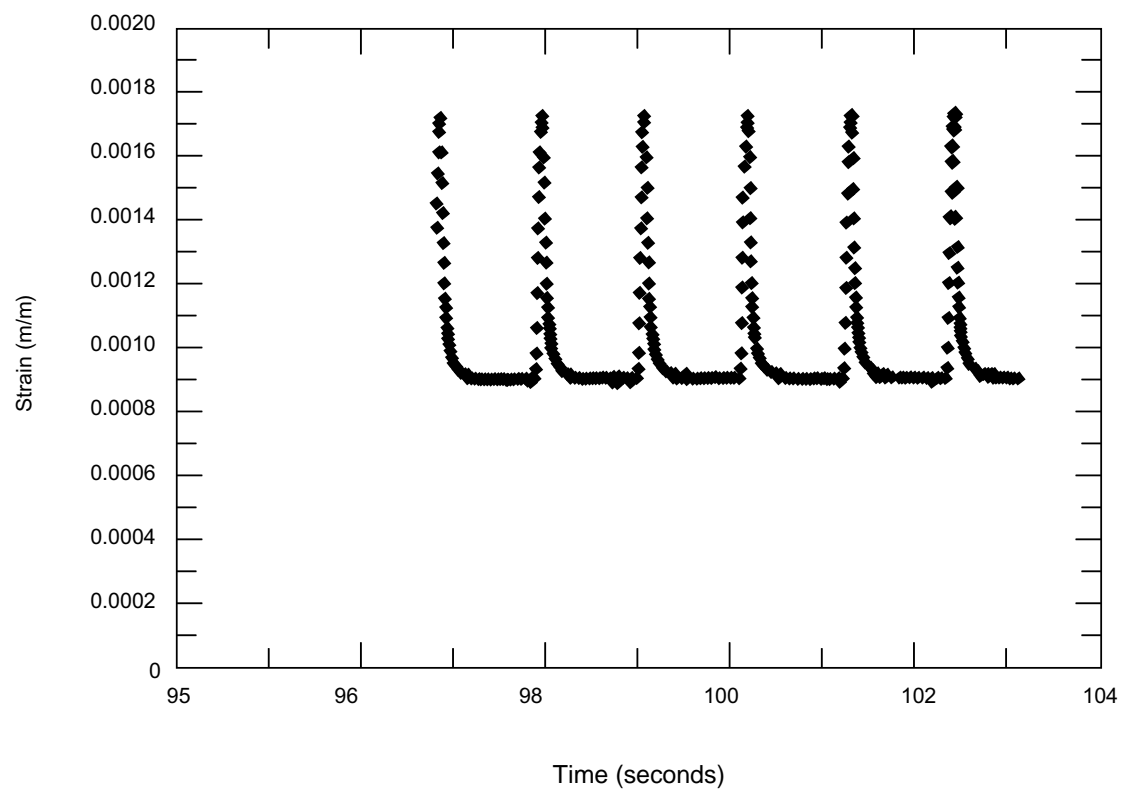

Figure 13. Corresponding strain measurement during resilient modulus test.

where $\sigma_{1}$ and $\sigma_{3}$ are the major and minor principal stresses and $\sigma_{d}$ is the deviator stress, which is equal to the difference of the major and minor principal stresses.

Changes in resilient modulus as a function of bulk stress are shown in Figure 14. The effect of void ratio (density) on resilient modulus is at most minimal for the $100 \%$ crushed aggregates (Fig. 14a). The effect of void ratio on resilient modulus can be seen with the $50 \%$ and $0 \%$ crushed aggregates (Fig. 14c, e).

A summary of resilient modulus as a function of bulk stress at near-constant void ratio is presented in Figure
15. Resilient modulus for the $50 \%$ crushed aggregate is an average of the resilient modulus obtained at void ratios 0.115 and 0.190 . It is assumed that the response of the $50 \%$ crushed aggregate at a void ratio of 0.152 is a linear interpolation between the two tests.

As seen in Figure 15, angularity somewhat influences the resilient modulus. At low bulk stresses, the difference between the natural material's resilient modulus is about $30 \%$ higher than the crushed material's resilient modulus. At bulk stresses higher than $300 \mathrm{MPa}$, 


\begin{tabular}{|c|c|c|c|c|c|}
\hline $\begin{array}{l}\text { Sequence } \\
\text { no. }\end{array}$ & $\begin{array}{c}\text { Confining } \\
\text { pressure } \\
(\mathrm{kPa})\end{array}$ & $\begin{array}{c}\text { Maximum } \\
\text { axial stress } \\
(\mathrm{kPa})\end{array}$ & $\begin{array}{c}\text { Cyclic } \\
\text { stress } \\
(\mathrm{kPa})\end{array}$ & $\begin{array}{c}\text { Contact } \\
\text { stress } \\
(\mathrm{kPa})\end{array}$ & $\begin{array}{c}\text { Number of } \\
\text { load } \\
\text { applications }\end{array}$ \\
\hline 0 & 103.4 & 103.4 & 93.1 & 10.3 & $500-1000$ \\
\hline 1 & 20.7 & 20.7 & 2.7 & 2.1 & 100 \\
\hline 2 & 20.7 & 41.4 & 5.4 & 4.1 & 100 \\
\hline 3 & 20.7 & 62.1 & 8.1 & 6.2 & 100 \\
\hline 4 & 34.5 & 34.5 & 31.0 & 3.5 & 100 \\
\hline 5 & 34.5 & 68.9 & 62.0 & 6.9 & 100 \\
\hline 6 & 34.5 & 103.4 & 93.1 & 10.3 & 100 \\
\hline 7 & 68.9 & 68.9 & 62.0 & 6.9 & 100 \\
\hline 8 & 68.9 & 137.9 & 124.1 & 13.8 & 100 \\
\hline 9 & 68.9 & 206.8 & 186.1 & 20.7 & 100 \\
\hline 10 & 103.4 & 68.9 & 52.0 & 6.9 & 100 \\
\hline 11 & 103.4 & 103.4 & 93.1 & 10.3 & 100 \\
\hline 12 & 103.4 & 206.8 & 186.1 & 20.7 & 100 \\
\hline 13 & 137.9 & 103.4 & 93.1 & 10.3 & 100 \\
\hline 14 & 137.9 & 137.9 & 124.1 & 13.8 & 100 \\
\hline 15 & 137.9 & 275.8 & 248.2 & 27.6 & 100 \\
\hline
\end{tabular}

Table 7. Test sample densities, moisture contents, and void ratios (300-mm-diameter sample).

\begin{tabular}{|c|c|c|c|c|c|}
\hline \multirow{2}{*}{$\begin{array}{c}\% \\
\text { crushed }\end{array}$} & \multirow{2}{*}{$\begin{array}{c}\text { Optimum } \\
\text { density } \\
\left(\mathrm{kg} / \mathrm{m}^{3}\right)\end{array}$} & \multicolumn{2}{|c|}{ Test density } & \multicolumn{2}{|c|}{ Void ratio } \\
\hline & & $\operatorname{Rep} 1$ & $\operatorname{Rep} 2$ & $\operatorname{Rep} 1$ & $\operatorname{Rep} 2$ \\
\hline 100 & 2319 & 2288 & 2433 & 0.158 & 0.089 \\
\hline 75 & 2346 & 2288 & 2288 & 0.155 & 0.158 \\
\hline 50 & 2349 & 2218 & 2376 & 0.190 & 0.1151 \\
\hline 25 & 2381 & 2277 & 2376 & 0.159 & \\
\hline 0 & 2404 & 2325 & 2348 & 0.137 & 0.129 \\
\hline$\%$ & $\begin{array}{c}\text { Optimum } \\
\text { moisture } \\
\text { content }\end{array}$ & $\begin{array}{r}\text { Targe } \\
\text { con } \\
\end{array}$ & $\begin{array}{l}\text { oisture } \\
\text { t (\%) }\end{array}$ & & \\
\hline crushed & (\%) & $\operatorname{Rep} 1$ & $\operatorname{Rep} 2$ & & \\
\hline 100 & 6.0 & 5.4 & 4.9 & & \\
\hline 75 & 5.0 & 5.0 & 5.0 & & \\
\hline 50 & 4.6 & 4.6 & 4.6 & & \\
\hline 25 & 5.0 & 5.1 & & & \\
\hline 0 & 6.0 & 4.9 & 4.9 & & \\
\hline
\end{tabular}

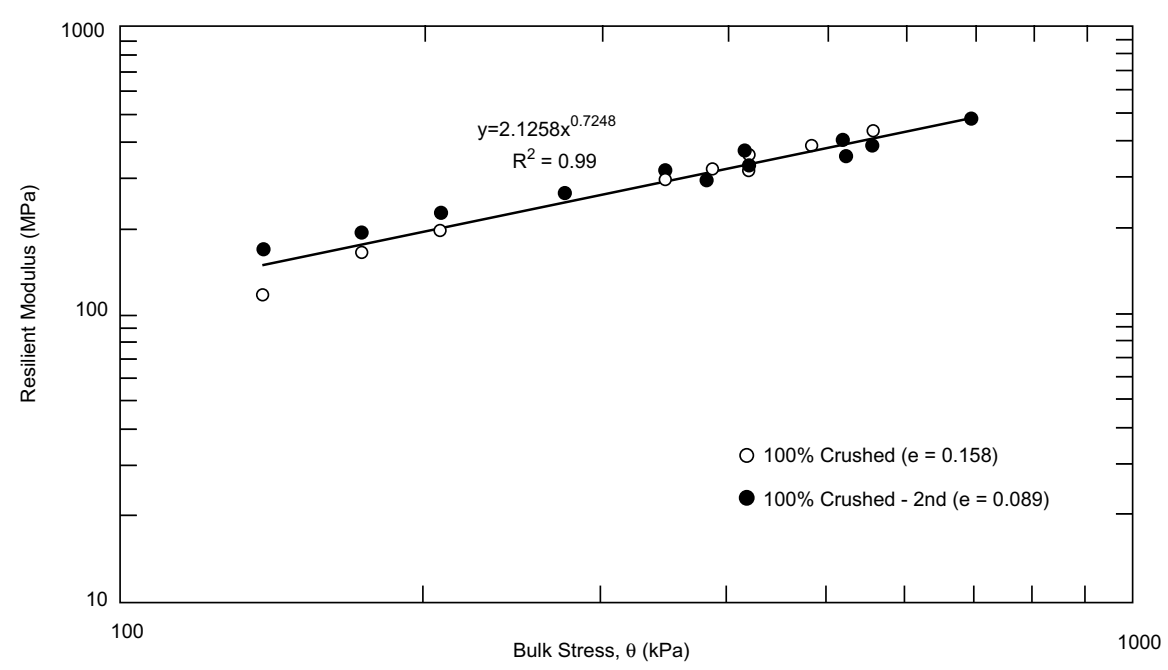

a. $100 \%$ crushed aggregates.

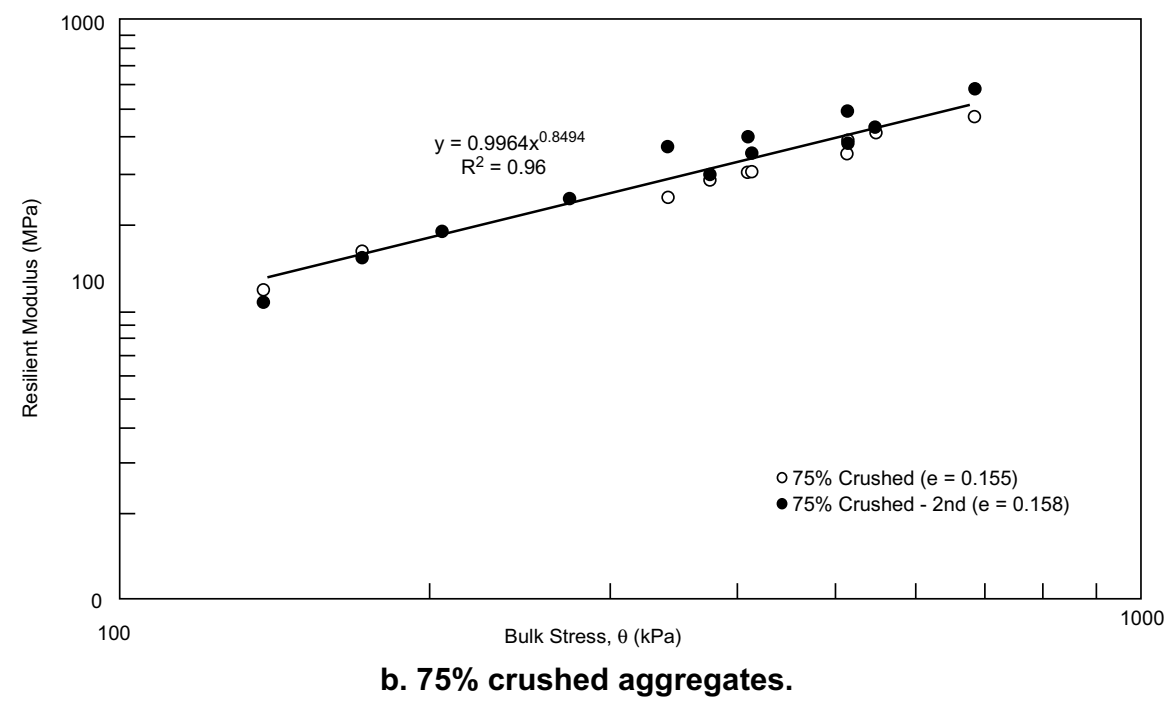

Figure 14. Resilient modulus as a function of bulk stress. 


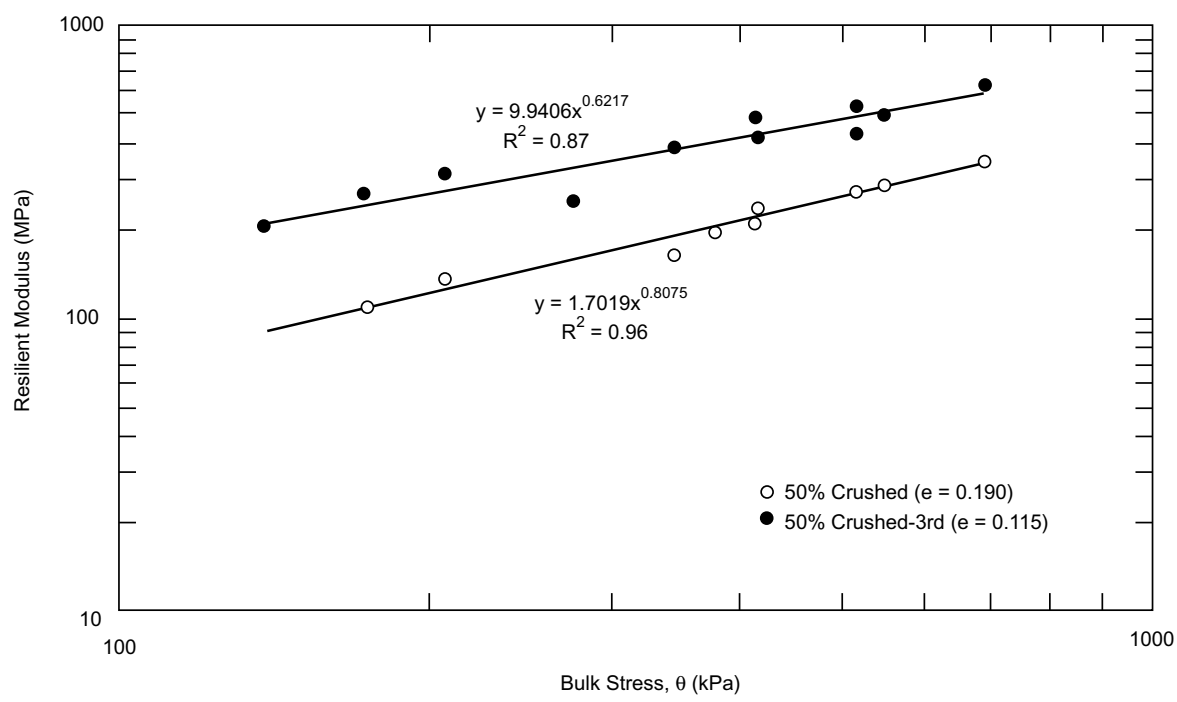

c. $50 \%$ crushed aggregates.

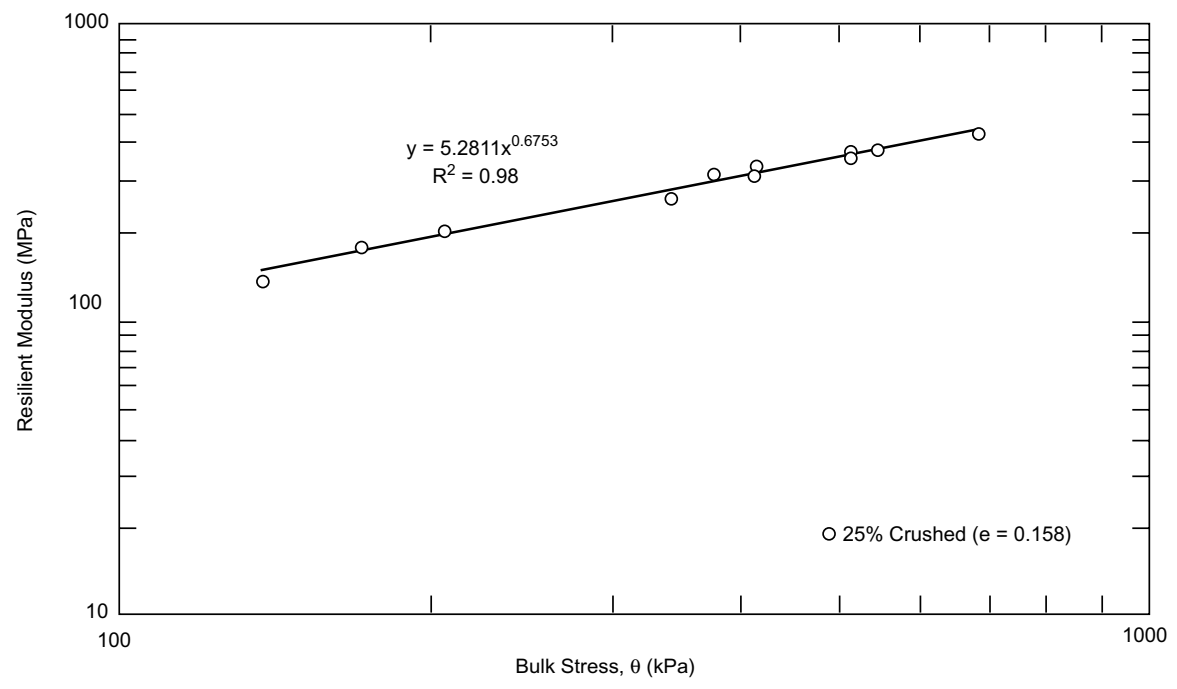

d. $25 \%$ crushed aggregates.

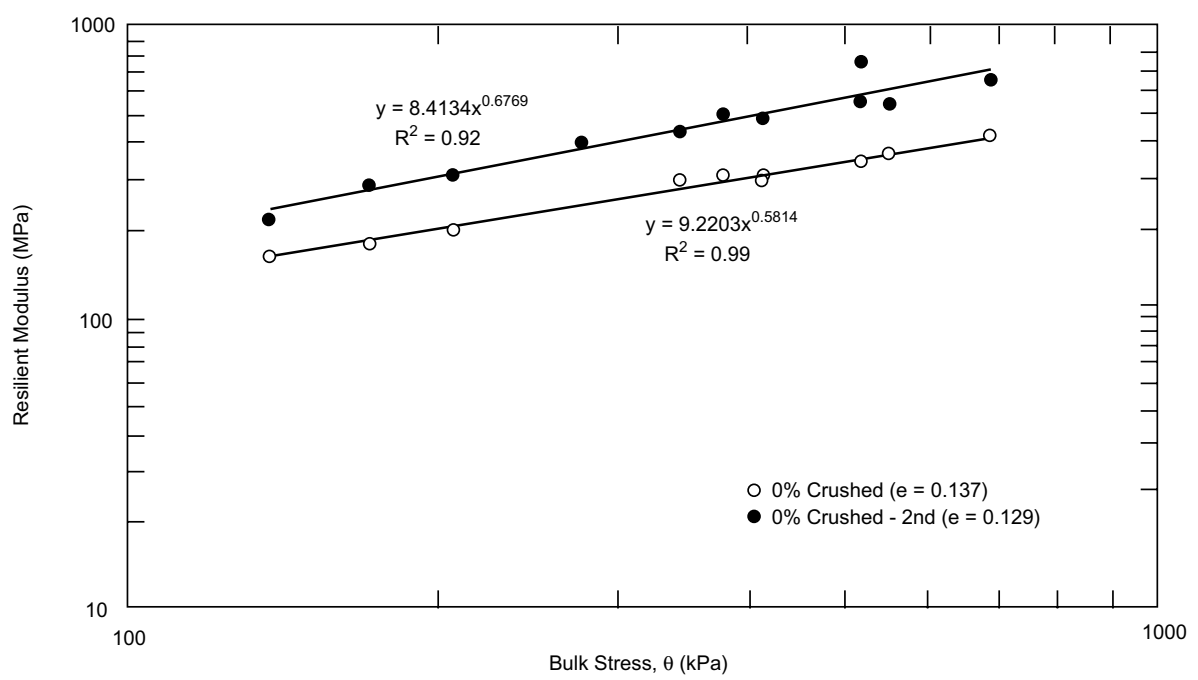

e. $0 \%$ crushed aggregates.

Figure 14. Resilient modulus as a function of bulk stress. 


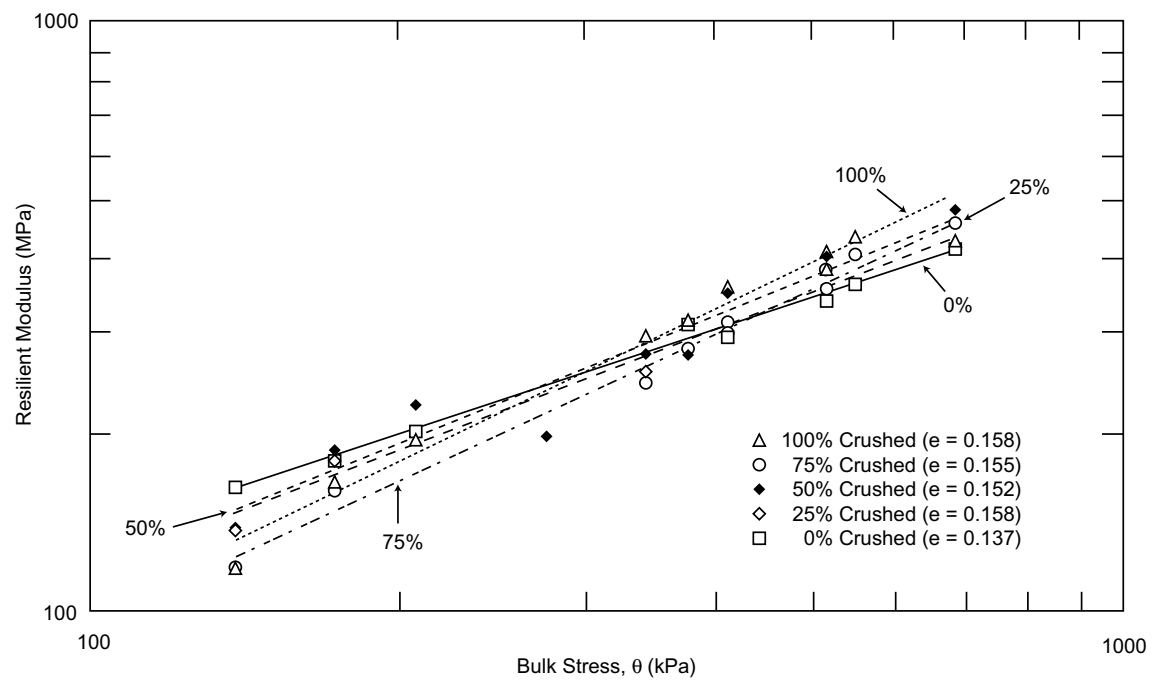

Figure 15. Resilient modulus as a function of bulk stress and aggregate angularity.

the reverse is true. The difference between the resilient modulus for crushed and natural material is small, approximately $10 \%$. This small difference can be attributed to the low deviator stresses used and, in turn, the materials are in the linear range. In conclusion, the effect of crushed material in a base course mix may not be significant.

For the

$$
M_{\mathrm{r}}=k_{1} \theta^{k_{2}}(\mathrm{MPa})
$$

model, coefficients $k_{1}$ and $k_{2}$ (Table 8) were obtained from a regression analysis using a power function.

A similar analysis was conducted with results from the 150-mm-diameter test samples (Fig. 16). The optimum and test densities, relative densities, target moisture contents, and void ratios for the various test samples are presented in Table 9. Our target density was the optimum density from T-99. The relative compaction of the test specimens ranged between 1.01 and 1.03, with most around 1.03. The average density of all test samples was $2179 \mathrm{~kg} / \mathrm{m}^{3}$ with a coefficient of variation $(\mathrm{COV})$ of $2.2 \%$. Target moisture contents ranged from 4.0 to $5.1 \%$ as shown in Table 9. Void ratios ranged from 0.180 to 0.268 with an average of 0.220 and a

\begin{tabular}{|c|c|c|c|c|}
\hline $\begin{array}{c}\% \\
\text { crushed }\end{array}$ & Void ratio & $\mathrm{k}_{1}$ & $\mathrm{k}_{2}$ & $\mathrm{R}^{2}$ \\
\hline 100 & $0.089-0.158$ & 4.2517 & 0.7248 & 0.99 \\
\hline 75 & 0.157 & 1.9928 & 0.8494 & 0.96 \\
\hline 50 & 0.115 & 9.9406 & 0.6217 & 0.87 \\
\hline 50 & 0.190 & 1.7019 & 0.8075 & 0.96 \\
\hline 25 & 0.158 & 5.2811 & 0.6753 & 0.98 \\
\hline 0 & 0.129 & 8.4134 & 0.6769 & 0.92 \\
\hline 0 & 0.137 & 9.2203 & 0.5814 & 0.99 \\
\hline
\end{tabular}

COV of $8 \%$.

Average density of the large-scale samples was 2316 $\mathrm{kg} / \mathrm{m}^{3}$, whereas average density of the 150 -mm-diameter samples was $2179 \mathrm{~kg} / \mathrm{m}^{3}$, a difference of approximately $6 \%$. In both cases, moisture content was on the dry side of optimum. Average void ratios of the large-scale and 150 -mm-diameter samples were 0.143 and 0.220 , respectively.

Average resilient moduli from the two tests are presented in Table 10. Individual test results are presented in Appendix B. Strain measurements at the 21-kPa confining pressure and $21-\mathrm{kPa}$ deviator stress were in most cases extremely noisy and were not used in the analy-

\begin{tabular}{|c|c|c|c|c|c|c|c|c|c|c|}
\hline \multirow{2}{*}{$\begin{array}{c}\% \\
\text { crushed }\end{array}$} & \multirow{2}{*}{$\begin{array}{c}\text { Optimum } \\
\text { density } \\
\left(\mathrm{kg} / \mathrm{m}^{3}\right)\end{array}$} & \multicolumn{2}{|c|}{ Test density $\left(\mathrm{kg} / \mathrm{m}^{3}\right)$} & \multicolumn{2}{|c|}{ Relative density } & \multirow{2}{*}{$\begin{array}{l}\text { Optimum } \\
\text { moisture } \\
\text { content (\%) }\end{array}$} & \multicolumn{2}{|c|}{$\begin{array}{c}\text { Target } \\
\text { moisture } \\
\text { content (\%) }\end{array}$} & \multicolumn{2}{|c|}{ Void ratio } \\
\hline & & $\operatorname{Rep} 1$ & $\operatorname{Rep} 2$ & $\operatorname{Rep} 1$ & $\operatorname{Rep} 2$ & & $\operatorname{Rep} 1$ & $\operatorname{Rep} 2$ & $\operatorname{Rep} 1$ & $\operatorname{Rep} 2$ \\
\hline 100 & 2030 & 2090 & & 1.03 & & 4.0 & 4.6 & & 0.268 & \\
\hline 75 & 2129 & 2178 & 2153 & 1.02 & 1.01 & 5.1 & 4.9 & 5.1 & 0.217 & 0.231 \\
\hline 50 & 2118 & 2174 & 2153 & 1.03 & 1.02 & 4.7 & 4.7 & 4.7 & 0.219 & 0.231 \\
\hline 25 & 2100 & 2157 & 2170 & 1.03 & 1.03 & 4.9 & 5.1 & 4.9 & 0.267 & 0.221 \\
\hline 0 & 2187 & 2245 & 2232 & 1.03 & 1.02 & 4.6 & 4.0 & 4.0 & 0.180 & 0.187 \\
\hline 0 & 2187 & & 2243 & & 1.03 & 4.6 & & 4.0 & 0.182 & \\
\hline
\end{tabular}




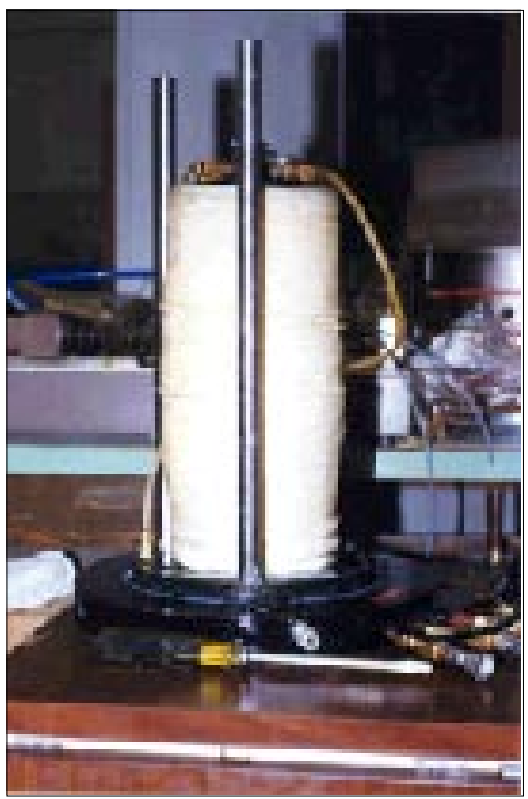

Figure 16. 150-mm-diameter test specimen at the end of testing.

sis. Other missing data in Table 10 indicate that the strain measurements were noisy and were not used in the calculations for resilient modulus.

The change in average resilient modulus as a function of bulk stress is shown in Figure 17. Individual regression power equations were fitted to the data and the coefficients $\left(k_{1}\right.$ and $\left.k_{2}\right)$ are presented in Table 11 . However, upon review, it is possible to combine the data into two trends. One group includes the 0 and $25 \%$ crushed aggregates and the second group contains the 50,75 , and $100 \%$ crushed aggregates. For these two

\begin{tabular}{|c|c|c|c|}
\hline $\begin{array}{l}\text { Table } \\
\text { cients } \\
\text { model } \\
\text { sample }\end{array}$ & $\begin{array}{l}\text { 1. Regr } \\
1 \text { and } \\
(150- \\
) .\end{array}$ & $\begin{array}{l}\text { ision } \\
\text { for ( } \\
\text { m-di }\end{array}$ & $\begin{array}{l}\text { effi- } \\
-\theta) \\
\text { eter }\end{array}$ \\
\hline $\begin{array}{c}\% \\
\text { crushed }\end{array}$ & $\mathrm{k}_{1}$ & $\mathrm{k}_{2}$ & $\mathrm{R}^{2}$ \\
\hline 100 & 29.396 & 0.417 & 0.70 \\
\hline 75 & 9.8145 & 0.628 & 0.93 \\
\hline 50 & 12.752 & 0.576 & 0.93 \\
\hline 25 & 7.5508 & 0.711 & 0.90 \\
\hline 0 & 25.237 & 0.468 & 0.86 \\
\hline
\end{tabular}

groups, $k_{1}$ and $k_{2}$ are $13.647,0.591\left(\mathrm{R}^{2}=0.79\right)$, and $15.438,0.540\left(\mathrm{R}^{2}=0.84\right)$, respectively.

Compared with the results from the large-scale tests, the data from the $150-\mathrm{mm}$ samples show that the resilient modulus is highest with the 0 and $25 \%$ crushed aggregate mixtures. A possible reason for the higher resilient modulus for the $100 \%$ natural aggregates could be the lower void ratio. It is interesting to note that the $50 \%$ crushed aggregates had the lowest resilient modulus at the same void ratio. The $100 \%$ crushed aggregate had a lower resilient modulus than the $100 \%$ natural material.

The effect of specimen size on resilient modulus is shown in Figure 18 for three levels of crushed aggregates. In general, resilient modulus from the smaller diameter samples was higher than that from the larger samples, even though void ratios for the $300-\mathrm{mm}$ samples were lower. The results agree with Sweere's (1990) findings. Generally, the difference is higher at the lower stress levels, ranging anywhere from 35 to $50 \%$.

\section{Shear strength}

At the end of the resilient modulus test, shear strength

\begin{tabular}{|c|c|c|c|c|c|c|c|}
\hline \multirow[b]{2}{*}{$\begin{array}{l}\text { Confining } \\
\text { pressure } \\
(\mathrm{kPa})\end{array}$} & \multirow[b]{2}{*}{$\begin{array}{c}\text { Deviator } \\
\text { stress } \\
\text { (kPa) }\end{array}$} & \multirow[b]{2}{*}{$\begin{array}{l}\text { Bulk } \\
\text { stress } \\
(\mathrm{kPa})\end{array}$} & \multicolumn{3}{|c|}{ Resilient modulus (MPa) } & \multirow[b]{2}{*}{$\begin{array}{c}25 \% \\
\text { crushed } \\
e=0.244\end{array}$} & \multirow[b]{2}{*}{$\begin{array}{c}0 \% \\
\text { crushed } \\
e=0.183\end{array}$} \\
\hline & & & $\begin{array}{c}100 \% \\
\text { crushed } \\
e=0.268\end{array}$ & $\begin{array}{c}75 \% \\
\text { crushed } \\
e=0.224\end{array}$ & $\begin{array}{c}50 \% \\
\text { crushed } \\
e=0.225\end{array}$ & & \\
\hline 21 & 21 & 83 & & & & & \\
\hline 21 & 41 & 103 & 183 & 184 & 166 & 187 & 193 \\
\hline 21 & 62 & 124 & 171 & 186 & 186 & 209 & 253 \\
\hline 34 & 34 & 138 & 247 & 237 & 241 & & 383 \\
\hline 34 & 69 & 172 & 287 & 248 & 289 & & 311 \\
\hline 34 & 103 & 207 & 249 & 255 & 250 & 364 & 265 \\
\hline 69 & 69 & 276 & 420 & 420 & 387 & 563 & 424 \\
\hline 69 & 138 & 345 & 375 & 346 & 353 & 473 & 385 \\
\hline 69 & 207 & 414 & 323 & 364 & 389 & 452 & 365 \\
\hline 103 & 69 & 379 & 430 & 433 & 417 & 624 & 445 \\
\hline 103 & 103 & 414 & 390 & 394 & 377 & 517 & 456 \\
\hline 103 & 207 & 517 & 317 & 484 & 466 & 578 & 447 \\
\hline 138 & 103 & 517 & 440 & 549 & 438 & 678 & 533 \\
\hline 138 & 138 & 552 & 378 & 532 & 508 & 691 & 438 \\
\hline 138 & 276 & 689 & 380 & 611 & 540 & & \\
\hline
\end{tabular}


Figure 17. Resilient modulus as a function of bulk stress and aggregate angularity, 150-mmdiameter samples.

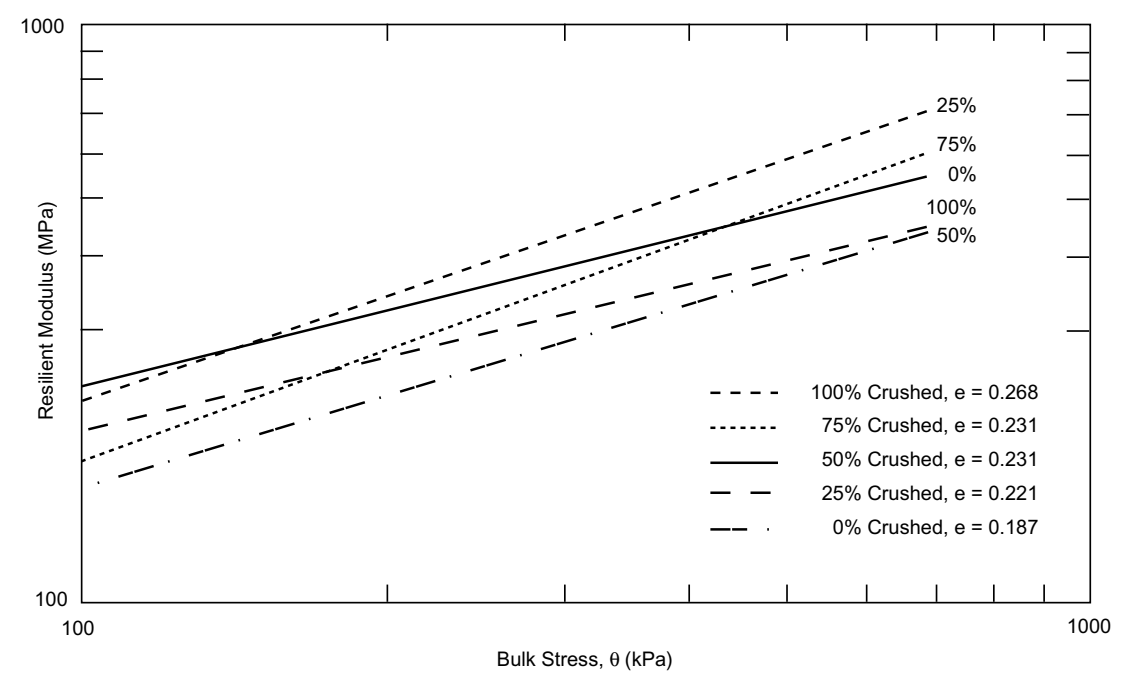

tests were conducted at a constant strain rate of $1 \%$ per minute. Typical stress and strain results are shown in Figure 19. Tests were conducted at approximately 35 $\mathrm{kPa}$ or $70 \mathrm{kPa}$ confining pressure. The measured $\sigma_{3 \mathrm{f}}$ and $\tau_{\max }$ are presented in Table 12. The angle of internal friction and cohesion was obtained from Mohr circles; examples are shown in Figures 20 and 21. As seen in Table 12, the angle of internal fricton $(\phi)$ varied between $31^{\circ}$ and $51^{\circ}$, with the $100 \%$ natural material having the lowest value. We were unable to calculate shear properties for the $0 \%$ natural ( $100 \%$ crushed) and $75 \%$ natural $(25 \%$ crushed) material from the tests because of the large difference in void ratios between the two samples. Based on the other test results, we estimated the angle of internal friction for the $100 \%$ crushed material with a void ratio of 0.16 to be about $51^{\circ}$ or higher. There is some apparent cohesion of material and this cohesion was the highest for the $100 \%$ natural material (Table 12).

A similar set of results from the 150-mm-diameter specimens are presented in Table 13 . The angle of internal friction varied between 41 and $46^{\circ}$ for void ratios around 0.22 . For the $100 \%$ natural material (void ratio of 0.18 ), the angle was $53^{\circ}$. Note that for the $300-\mathrm{mm}$ diameter samples, $\phi$ was smallest when the percentage of crushed material was zero. In this case, $\phi$ is highest when the percentage of crushed material is zero.

The maximum shear stress $\left(\tau_{\max }\right)$ and the angle of internal friction are more a function of void ratio and less a function of percentage of crushed material as shown by the results plotted in Figures 22 and 23. In Figures 22 and 23, the values next to the figures indicate the percentage of crushed material in the aggregate mixture. Clearly, from these results the percentage of crushed material has no direct correlation to the maximum shear stress. Another observation made with the 300-mm-diameter samples tests (Fig. 22) is that the effect of the higher confining pressure $(70 \mathrm{kPa})$ tends
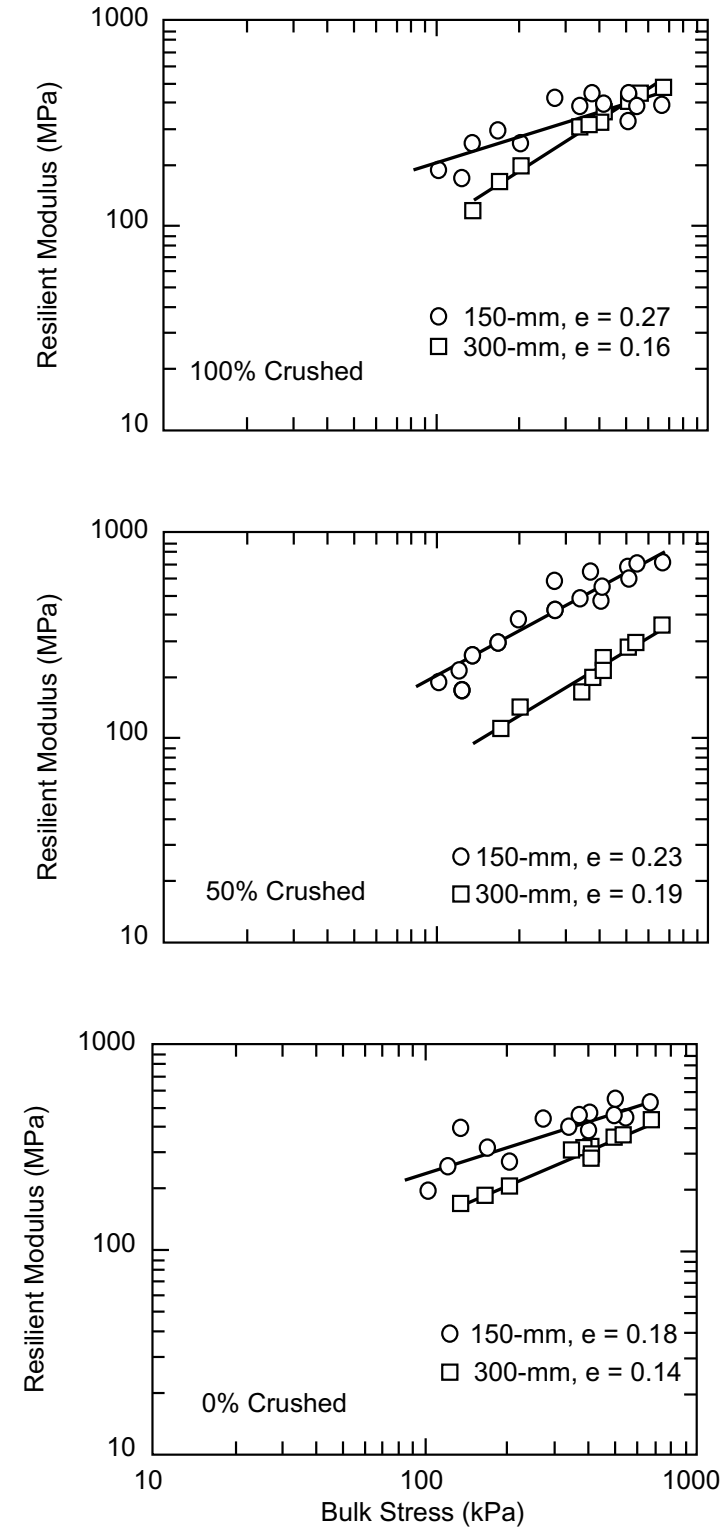

Figure 18. Effect of specimen size on resilient modulus. 

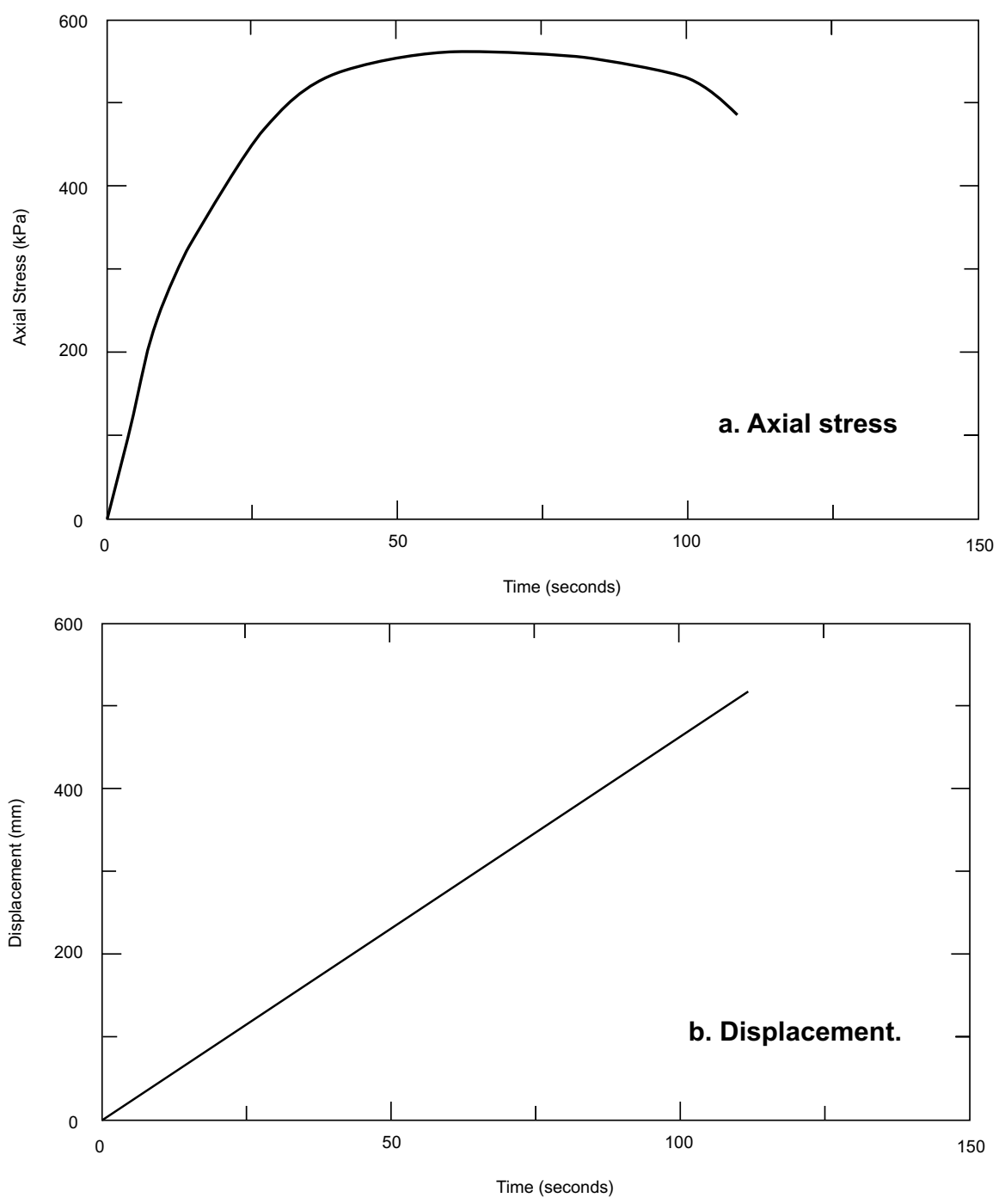

Figure 19. Typical measurements $\left(100 \%\right.$ natural, $\left.\sigma_{3}=73 \mathrm{kPa}\right)$.

\begin{tabular}{|c|c|c|c|c|c|}
\hline $\begin{array}{c}\text { Test } \\
\text { (\% } \\
\text { crushed) }\end{array}$ & $\begin{array}{l}\text { Void } \\
\text { ratio }\end{array}$ & $\begin{array}{c}\sigma_{3 f} \\
(k P a)\end{array}$ & $\begin{array}{c}\left(\tau_{\max }\right)_{\mathrm{f}} \\
(\mathrm{kPa})\end{array}$ & $\phi$ & $\begin{array}{c}\mathrm{C} \\
(\mathrm{kPa})\end{array}$ \\
\hline 100 (rep 1) & 0.158 & 35 & 279 & $\left(51^{\circ}\right)$ & \\
\hline 100 (rep 2) & 0.089 & 73 & 560 & & \\
\hline 75 (rep 1) & 0.155 & 37 & 273 & $51^{\circ}$ & 51 \\
\hline 75 (rep 2) & 0.158 & 69 & 385 & & \\
\hline 50 (rep 1) & 0.190 & 34 & 151 & $50^{\circ}$ & 15 \\
\hline 50 (rep 2) & 0.147 & 72 & 273 & & \\
\hline 50 (rep 3) & 0.115 & 37 & 339 & & \\
\hline 25 (rep 1) & 0.159 & 37 & 283 & & \\
\hline 25 (rep 2) & 0.085 & 70 & 578 & & \\
\hline 0 (rep 1) & 0.137 & 33 & 265 & $31^{\circ}$ & 129 \\
\hline 0 (rep 2) & 0.129 & 73 & 308 & & \\
\hline
\end{tabular}

to shift upward on the same curve as the $36 \mathrm{kPa}$, unlike the distinct difference seen with the 150 -mm-diameter sample results (Fig. 22).

The effect of void ratio and percentage of crushed material in the aggregate mixture on the mixture's shear strength is presented in Table 14 and Figure 23. For the 300-mm samples, shear strength decreases rapidly with increasing void ratio. A similar but less rapid response than that seen with the 300 -mm-diameter samples is seen with the 150 -mm samples when the confining pressure is $70 \mathrm{kPa}$. At the lower confining pressure of 36 $\mathrm{kPa}$, shear strength is unaffected by the void ratio (Fig. 23). As with the maximum shear stress, the correlation between the percent crushed aggregate and shear strength is poor (Fig. 23). 


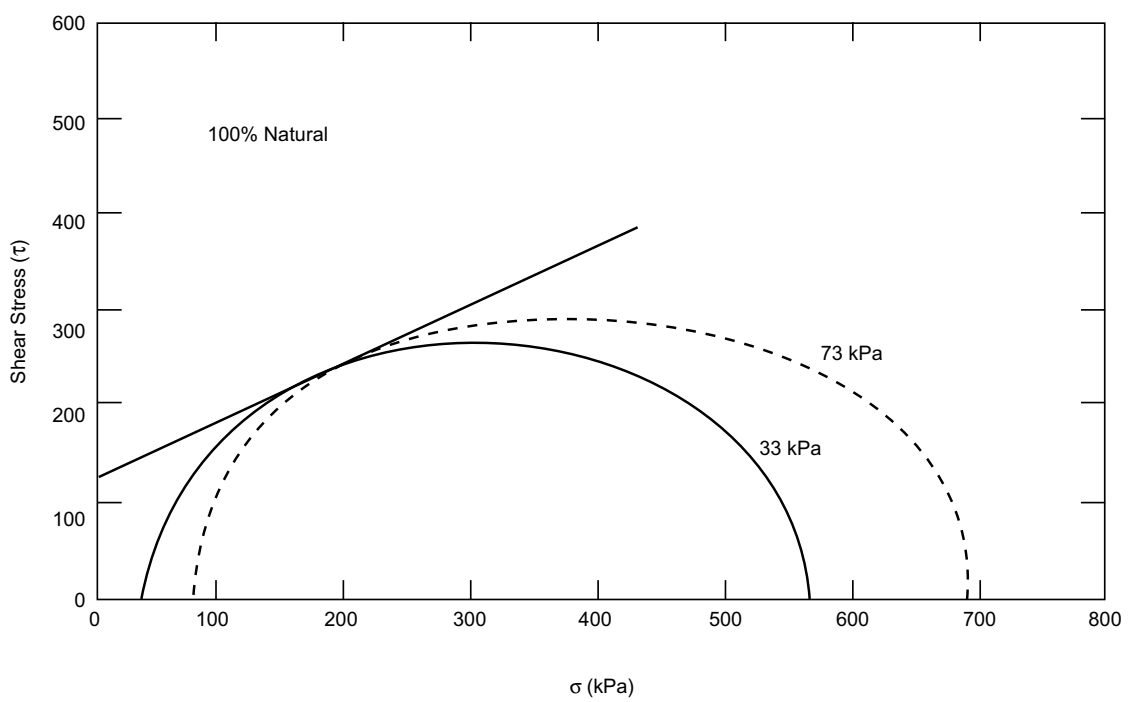

Figure 20 . Mohr circles for $100 \%$ natural materials (300-mm-diameter samples).

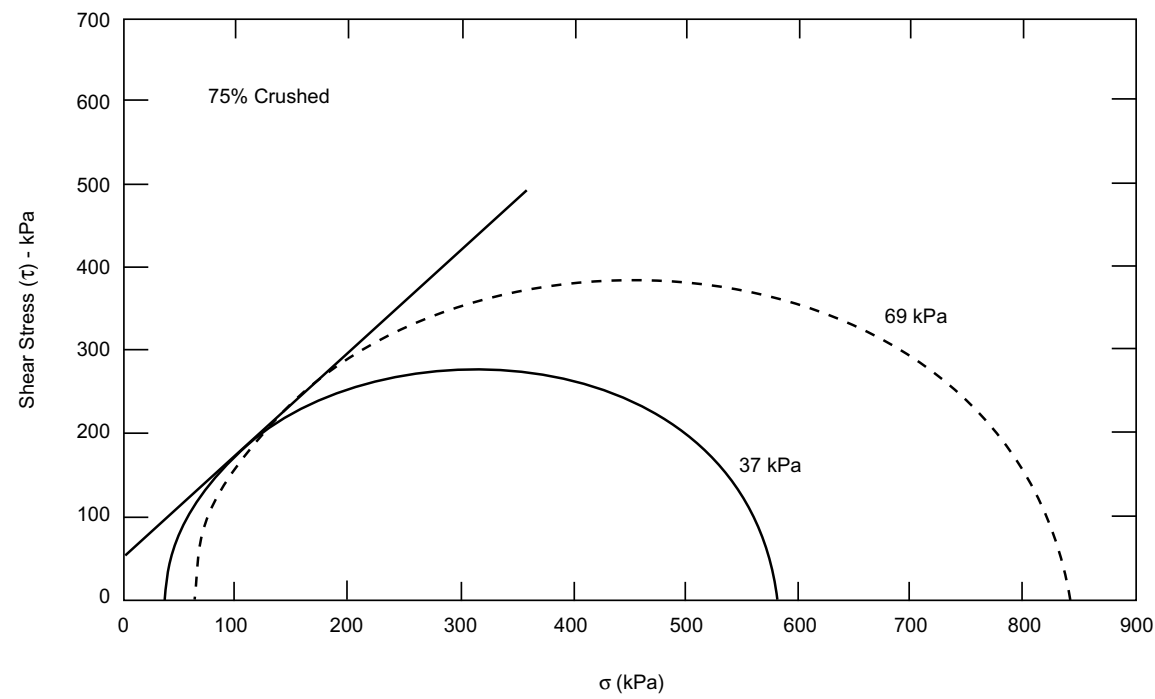

Figure 21. Mohr circles for $25 \%$ natural materials (300-mm-diameter samples).

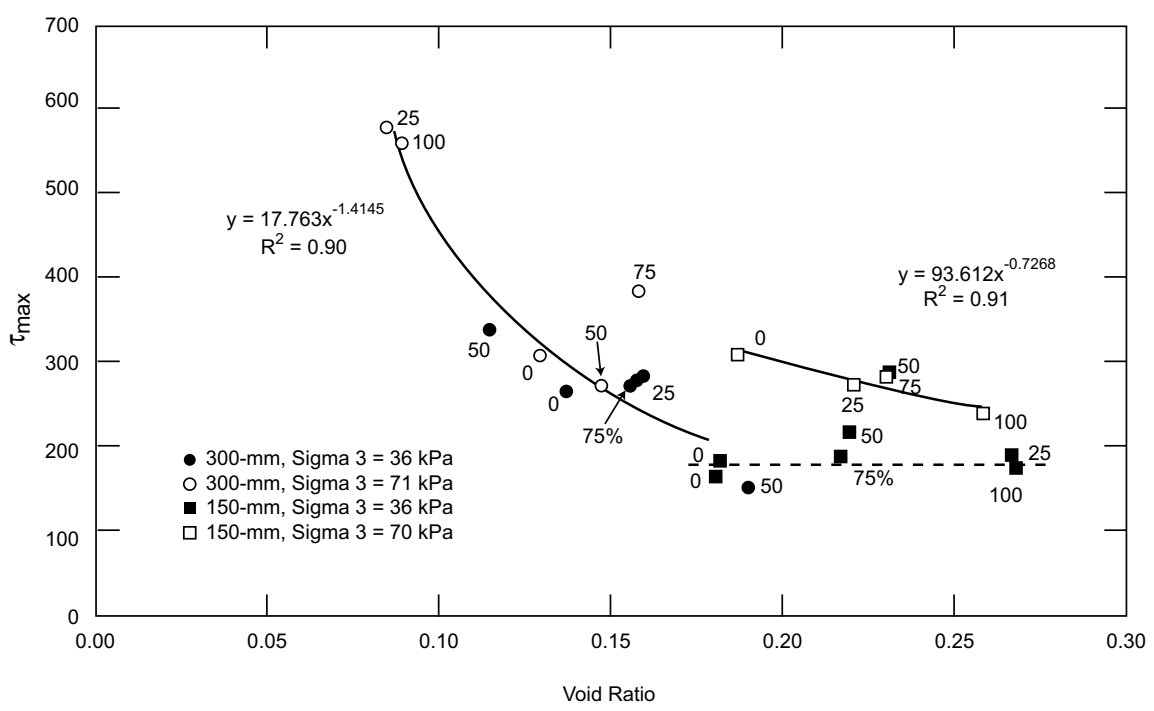

Figure 22. Influence of void ratio on maximum shear stress. 


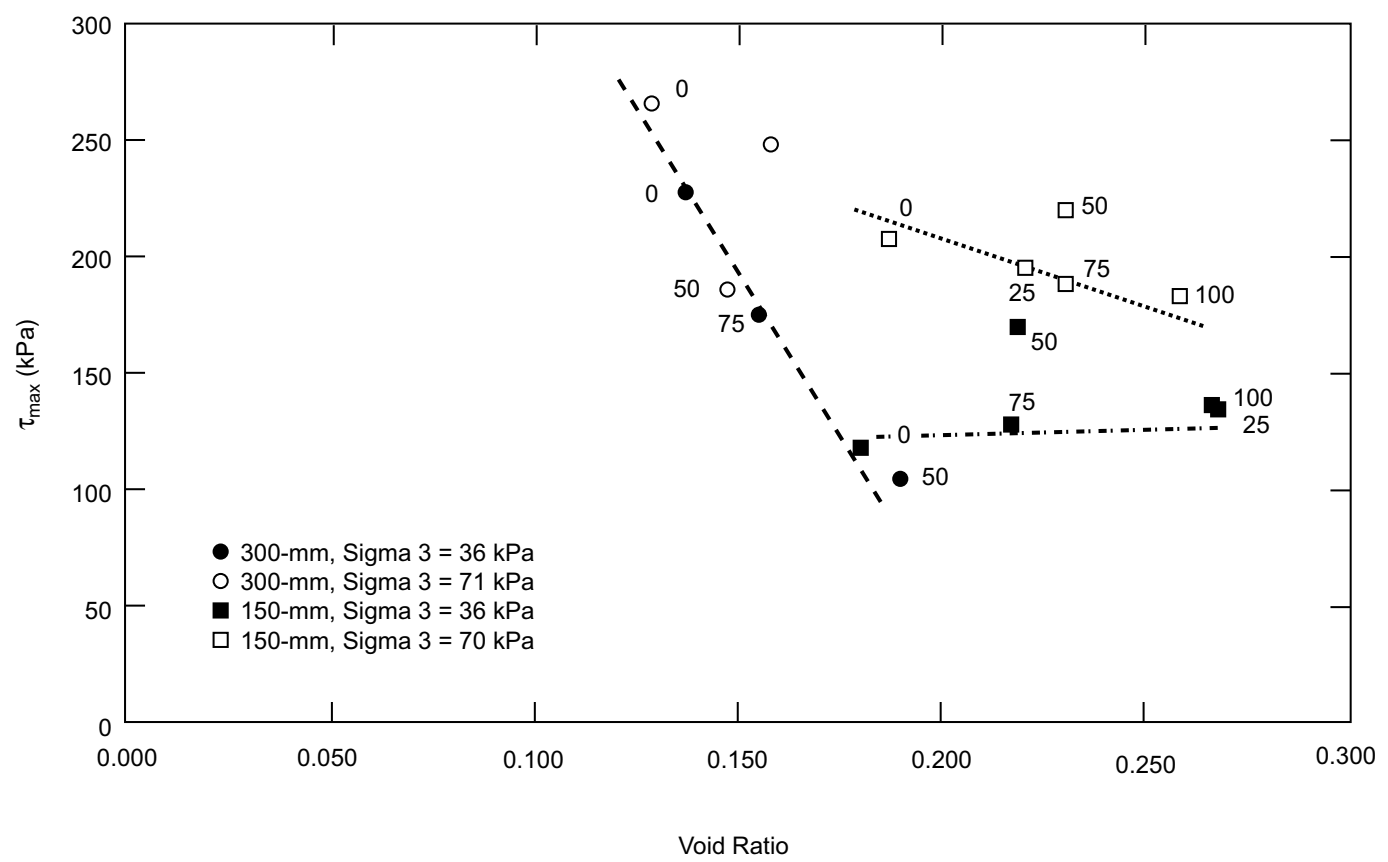

Figure 23. Effect of percent crushed aggregate, sample size, and void ratio on the maximum shear stress.

\begin{tabular}{|c|c|c|c|c|c|}
\hline $\begin{array}{c}\text { Test } \\
(\% \\
\text { crushed }\end{array}$ & $\begin{array}{l}\text { Void } \\
\text { ratio }\end{array}$ & $\begin{array}{c}\sigma_{3 f} \\
(\mathrm{kPa})\end{array}$ & $\begin{array}{c}\tau_{\max } \\
(k P a)\end{array}$ & $\phi$ & $\begin{array}{c}\mathrm{C} \\
(\mathrm{kPa})\end{array}$ \\
\hline $\begin{array}{l}100 \text { (rep 1) } \\
100 \text { (rep 2) }\end{array}$ & $\begin{array}{l}0.268 \\
0.258\end{array}$ & $\begin{array}{l}34 \\
68\end{array}$ & $\begin{array}{l}177 \\
243\end{array}$ & 41 & 51 \\
\hline $\begin{array}{l}75 \text { (rep 1) } \\
75 \text { (rep 2) }\end{array}$ & $\begin{array}{l}0.217 \\
0.231\end{array}$ & $\begin{array}{l}37 \\
70\end{array}$ & $\begin{array}{l}190 \\
278\end{array}$ & 46 & 37 \\
\hline $\begin{array}{l}50 \text { (rep 1) } \\
50 \text { (rep 2) }\end{array}$ & $\begin{array}{l}0.219 \\
0.231\end{array}$ & $\begin{array}{l}35 \\
69\end{array}$ & $\begin{array}{l}217 \\
281\end{array}$ & 41 & 68 \\
\hline $\begin{array}{l}25 \text { (rep 1) } \\
25 \text { (rep 2) }\end{array}$ & $\begin{array}{l}0.267 \\
0.221\end{array}$ & $\begin{array}{l}36 \\
70\end{array}$ & $\begin{array}{l}191 \\
276\end{array}$ & 45 & 42 \\
\hline $\begin{array}{l}0 \text { (rep 1) } \\
0 \text { (rep 2) } \\
0 \text { (rep 3) }\end{array}$ & $\begin{array}{l}0.180 \\
0.187 \\
0.182\end{array}$ & $\begin{array}{l}36 \\
69 \\
36\end{array}$ & $\begin{array}{l}165 \\
312 \\
186\end{array}$ & 53 & 29 \\
\hline
\end{tabular}

The effect of void ratio on the angle of internal friction for the $150-\mathrm{mm}$-diameter samples is that, with increasing void ratio, the angle of internal friction decreases (Fig. 24). This is in line with results for sands in the literature. However, with the $300-\mathrm{mm}$ samples, it appears from the limited data that the effect on the angle of internal friction $(\phi)$ is at most small when there is at least $50 \%$ crushed material present in the mixture. There is a significant difference between the $100 \%$ natural material and mixtures containing at least $50 \%$ crushed aggregates.

In summary, based on large-scale triaxial tests, the void ratio of the mixture has a significant effect on the shear strength of base course aggregates. There is no direct correlation between the percent of crushed mater-

\begin{tabular}{|c|c|c|c|}
\hline Sample & $\begin{array}{l}\text { Void } \\
\text { ratio }\end{array}$ & $\begin{array}{c}\sigma_{3} \\
(k P a)\end{array}$ & $\begin{array}{c}\tau \\
(\mathrm{kPa})\end{array}$ \\
\hline \multicolumn{4}{|l|}{ 300-mm samples } \\
\hline $75 \%$ crushed - rep 1 & 0.155 & 37 & 175 \\
\hline $75 \%$ crushed - rep 2 & 0.158 & 69 & 248 \\
\hline $50 \%$ crushed - rep 1 & 0.190 & 34 & 104 \\
\hline $50 \%$ crushed - rep 2 & 0.147 & 72 & 186 \\
\hline $0 \%$ crushed - rep 1 & 0.137 & 33 & 228 \\
\hline $0 \%$ crushed - rep 2 & 0.129 & 73 & 266 \\
\hline \multicolumn{4}{|l|}{ 150-mm samples } \\
\hline $100 \%$ crushed - rep 1 & 0.268 & 34 & 135 \\
\hline $100 \%$ crushed - rep 2 & 0.258 & 68 & 183 \\
\hline $75 \%$ crushed - rep 1 & 0.217 & 37 & 128 \\
\hline $75 \%$ crushed - rep 2 & 0.231 & 70 & 188 \\
\hline $50 \%$ crushed - rep 1 & 0.219 & 35 & 170 \\
\hline $50 \%$ crushed - rep 2 & 0.231 & 69 & 220 \\
\hline $25 \%$ crushed - rep 1 & 0.267 & 36 & 136 \\
\hline $25 \%$ crushed - rep 2 & 0.221 & 70 & 195 \\
\hline $0 \%$ crushed - rep 1 & 0.180 & 36 & 118 \\
\hline $0 \%$ crushed - rep 2 & 0.187 & 69 & 208 \\
\hline
\end{tabular}

ials and shear strength. The angle of internal friction for base course materials is not significantly affected when there is at least $50 \%$ crushed aggregate. There is significant difference between $100 \%$ natural material and material with at least $50 \%$ crushed aggregate.

\section{PARTICLE INDEX TESTS}

The particle index (PI) test is based on the idea that void ratio and rate of void change are affected by the aggregates' shape, angularity, and surface texture. The 


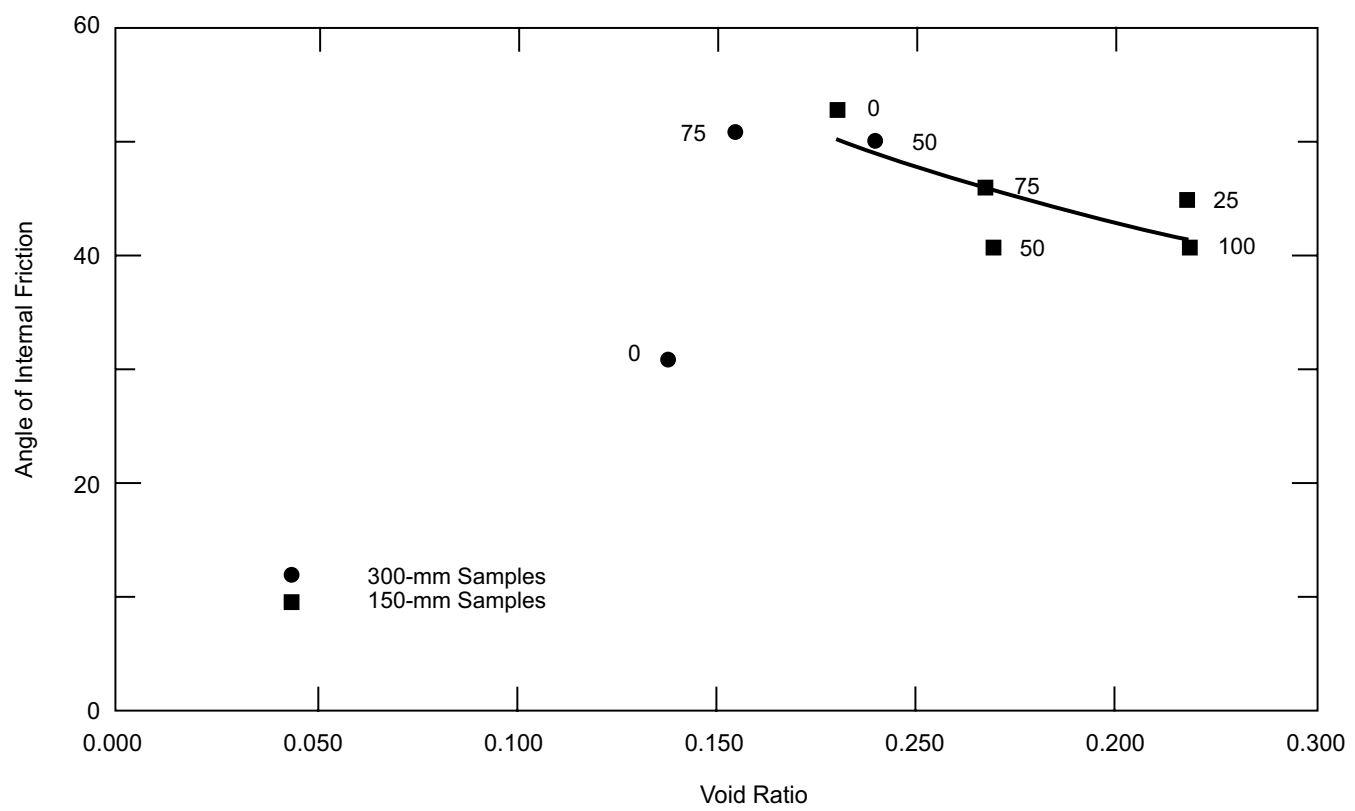

Figure 24. Effect of void ratio on the angle of internal friction.

original PI required that aggregates be separated into three sizes: passing the $3 / 4$-in. and retained on the $1 / 2^{-}$ in. sieve; passing the $1 / 2$-in. and retained on the $3 / 8$-in. sieve; and passing the $3 / 8^{-i n}$. and retained on the No. 4 sieve. For each size, the test involves tamping uniform aggregates into a mold in three equal layers using a standard tamping rod with 10 strokes per layer. The process was repeated with 50 strokes per layer. Based on the percentage of voids at two compaction levels, PI was calculated from

$$
\mathrm{PI}=1.25 V_{10}-0.25 V_{50}-32
$$

where $V_{10}=\%$ voids in aggregates, 10 strokes per layer, and $V_{50}=\%$ voids in aggregates, 50 strokes per layer.

Details on the development of the test method can be found in Huang (1965) and Janoo (1998).

Breaking the aggregates into various particle sizes is time consuming and expensive. A study conducted by Michigan Transportation Commission (1983) showed the following:

1. PI was more dependent on the aggregates' geometric properties than on gradation. PI values were significantly higher for crushed than for natural aggregates.

2. PI tests conducted on the total mixtures produced similar relative differences between crushed and natural aggregates (Fig. 25).

3. The PI showed less variation if based on the voids from the 10-blow compactive effort. The additional 50 blows were unnecessary.

Based on the results from the Michigan study, we decided to use the modified Michigan Test Method for determining PI. Tests were conducted on the $0,25,40$, $50,60,75$, and $100 \%$ crushed aggregate mixtures.
Approximately $23 \mathrm{~kg}$ of aggregate was required for the test. From the $23-\mathrm{kg}$ sample, we were able to get approximately $6 \mathrm{~kg}$ of aggregates, which were separated into coarse and fine fractions. Coarse aggregates passed the $38-\mathrm{mm}$ sieve but were retained on the $4.75-\mathrm{mm}$ sieve. Fine aggregates passed the $4.75-\mathrm{mm}$ sieve but were retained on the $0.6-\mathrm{mm}$ sieve.

The coarse aggregates were compacted in three equal layers in a steel cylindrical mold with an inside diameter of $150 \mathrm{~mm}$ and an inside height of $178 \mathrm{~mm}$ (Fig. 26). The layer had ten drops evenly distributed over the surface. The compaction effort was applied through a rounded rod with a hemisphere diameter of $16 \mathrm{~mm}$ and a length of $610 \mathrm{~mm}$. Each drop was made by holding the rod vertically with its rounded end $51 \mathrm{~mm}$ above the surface of the aggregate. At the end of the third layer compaction, the aggregate and mold was weighed and the amount of coarse aggregate to fill the mold was determined.

From the weight, the volume of voids was calculated from

$$
V_{10}=\left[1-\frac{W_{10}}{G_{\mathrm{sb}} V}\right] \times 100
$$

where $V_{10}=\%$ voids in aggregates at 10 strokes per layer

$W_{10}=$ average weight of aggregates in the mold

$G_{\mathrm{sb}}=$ bulk dry specific gravity

$V=$ volume of mold, $\mathrm{mL}$.

Based on the Michigan study, the modified PI is estimated from Figure 27 or from 


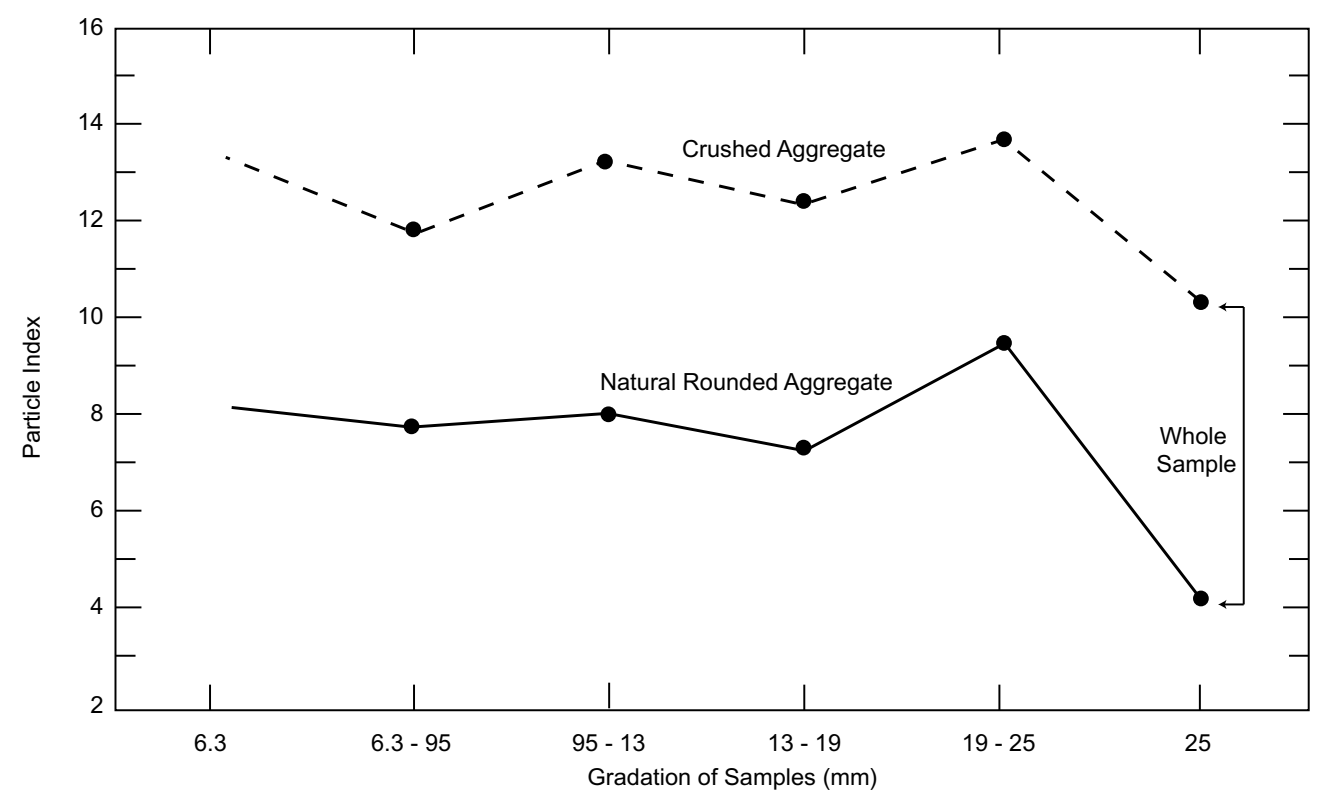

Figure 25. Particle index for different aggregate gradations. (After Michigan Transportation Commission 1983)

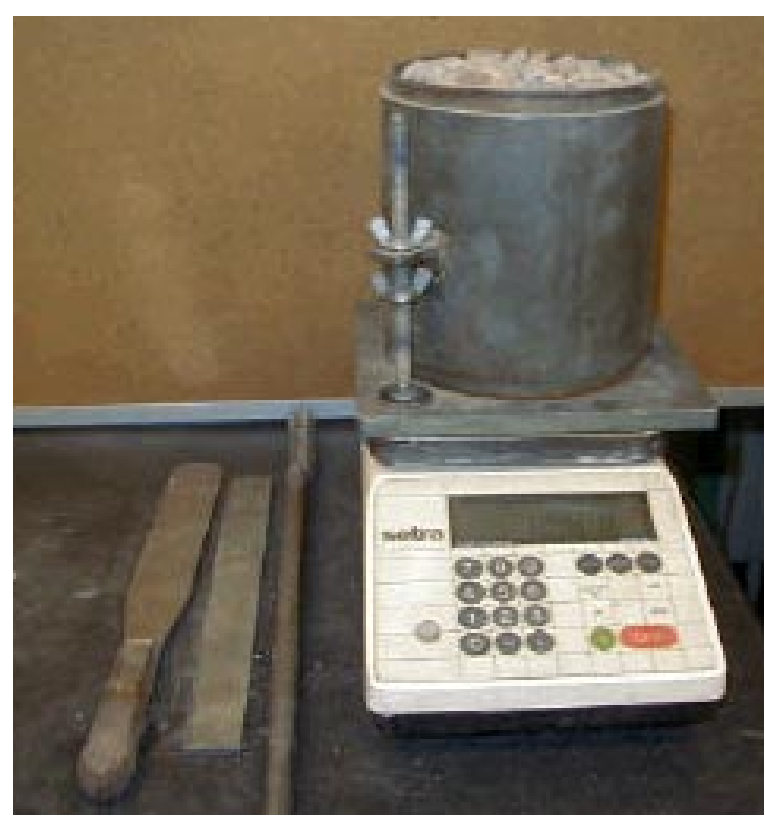

Figure 26. Particle index test mold.

$$
\mathrm{PI}=0.983 V_{10}-30 \text {. }
$$

Test results, presented in Appendix C, are from the aggregates shipped from ERDC/GSL after the completion of the resilient modulus and shear tests. However, additional tests were conducted on other natural and crushed aggregates. These results are presented in Table C1. Results from the first batch of aggregate samples and from additional tests done with 40 and $60 \%$ crushed aggregate mixtures on a second batch of material pro- vided by VAOT are shown in Figure 28. The results were significantly different and therefore warranted additional investigation.

A check was made on the percentage of the angular aggregates in the various mixtures. This was done visually using ASTM Standard D-2488, Visual Identification of Aggregate Angularity. The angularity of coarse aggregate is described as either angular, subangular, subrounded, or rounded. Additional details of this test procedure can be found in Janoo (1998). Visual inspections were conducted on the $0,40,50,60$, and $100 \%$ crushed aggregates mixtures. Examples of the different angularities of the test aggregates are shown in Figure 29. The results of the percent angularities in the three mixtures are presented in Figure 30.

For the $100 \%$ crushed aggregate mixture, we found that 82 of the aggregates were either subangular or angular. However, $18 \%$ consisted of subrounded aggregates. There were no rounded aggregates in the mixture. For the natural aggregates $(0 \%$ crushed), there was an almost $50-50$ split in angular and round aggregates. The round and subrounded aggregates equaled $52 \%$, with the remainder almost equally split between subangular and angular aggregates. For the 50-50 mixture, the split was $40 \%$ round and subrounded, and $60 \%$ angular and subangular aggregates. The percentage of round and subround material in the $40 / 60 \mathrm{crushed} /$ natural aggregate mixture turned out to contain $60 \%$ angular material and the $60 / 40$ crushed/natural aggregate mixture turned out to contain $80 \%$ angular material. Based on this investigation, there is a difference between crushed aggregates and angular aggregates. Angular materials may occur naturally, and basing the angularity of aggregates on per- 


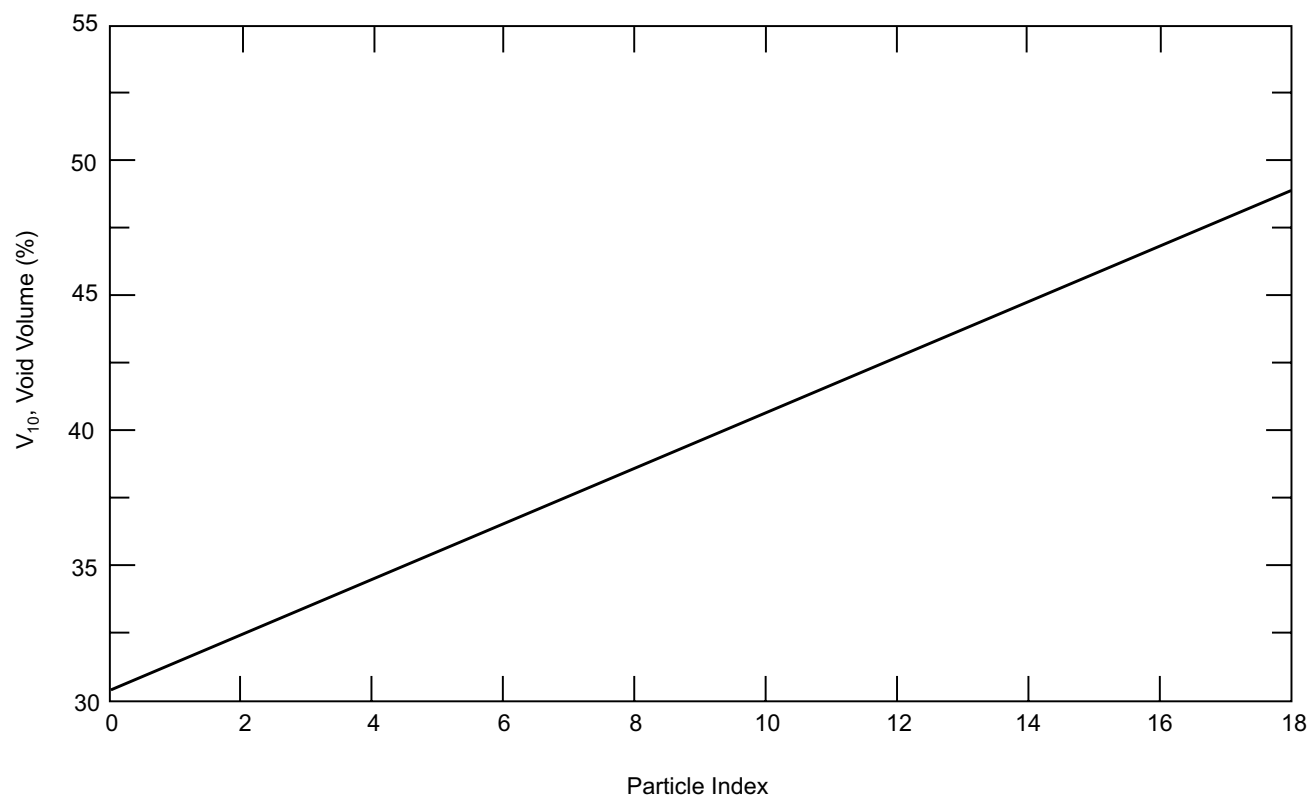

Figure 27. Void volume vs. particle index at a compactive effort of 10 blows per layer.

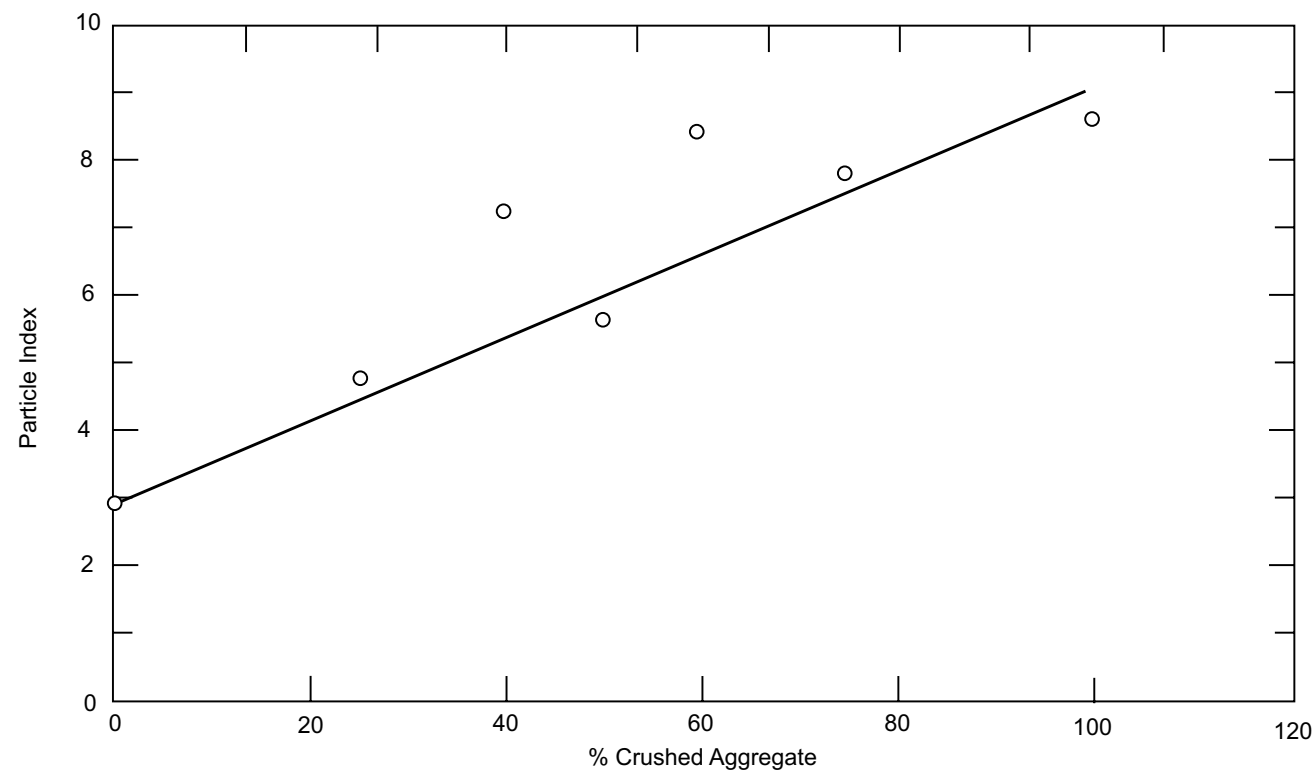

Figure 28. Relationship between particle index and percent crushed aggregate in mixture.

cent crushed aggregates may lead to erroneous results. The corrected percentage of crushed materials for the 40/60 and 60/40 crushed/natural aggregates and PI are shown in Figure 31. PI as a function of percentage of crushed aggregate can also be estimated from the following equation:

$$
\mathrm{PI}=0.601(\% \text { crushed })+3.124 .
$$

Average PI values for the coarse aggregates are presented in Table 15. PI for the aggregate mixture ranges between 2.9 and 8.6; the crushed aggregate content increases from 0 to $100 \%$. As seen in Table 15, the influ- ence of the percent of crushed fine aggregates on PI was minor.

The next step in the process was to determine whether we could relate PI to the aggregate mixture's mechanical properties. Resilient modulus from the $300-\mathrm{mm}-$ diameter tests at two bulk stress values was plotted as a function of PI (Fig. 32). The bulk stresses chosen were $400 \mathrm{kPa}$ and $200 \mathrm{kPa}$. These values were based on a theoretical analysis of a 100-mm asphalt concrete pavement over 600-mm base course over a weak subgrade. The modulus values used in the analysis were 2750 $\mathrm{MPa}, 345 \mathrm{MPa}$, and $35 \mathrm{MPa}$, respectively. Based on 


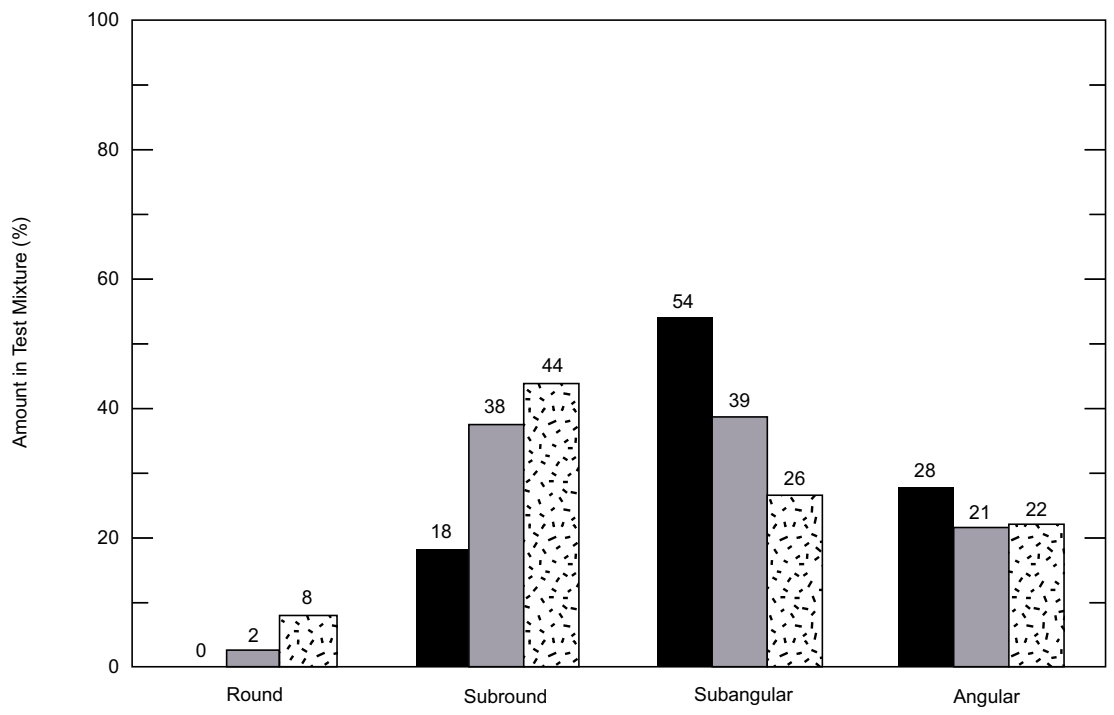

Figure 29. Examples of angularities in test aggregate.

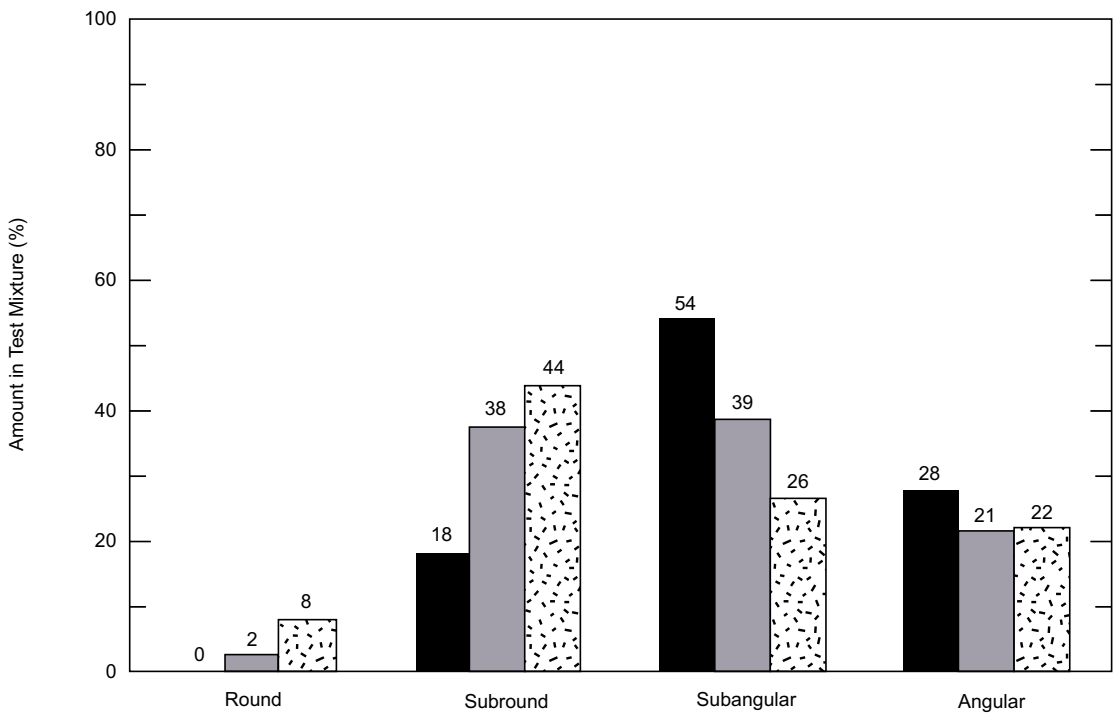

Figure 30. Percentage of round, subround, angular, and subangular aggregates in particle index test specimen.

\begin{tabular}{|c|c|c|c|c|}
\hline $\begin{array}{c}\% \\
\text { crushed }\end{array}$ & $\begin{array}{c}\text { Voids in } \\
\text { coarse } \\
\text { aggregates } \\
\text { (\%) }\end{array}$ & $\begin{array}{c}\text { Coarse } \\
\text { PI }\end{array}$ & $\begin{array}{l}\text { Voids in } \\
\text { fine } \\
\text { aggregates } \\
\text { (\%) }\end{array}$ & $\begin{array}{c}\text { Fine } \\
\text { PI }\end{array}$ \\
\hline 100 & 39.28 & 8.62 & 41.45 & 10.92 \\
\hline 80 & 39.07 & 8.41 & & \\
\hline 75 & 38.46 & 7.81 & 40.30 & 8.99 \\
\hline 60 & 37.93 & 7.29 & & \\
\hline 50 & 36.27 & 5.65 & 41.72 & 11.02 \\
\hline 25 & 35.39 & 4.80 & 39.66 & 9.62 \\
\hline 0 & 33.49 & 2.92 & 41.62 & 10.91 \\
\hline
\end{tabular}

this analysis, the bulk stress near the top of the base course was around $400 \mathrm{kPa}$ and was around $200 \mathrm{kPa}$ in the middle of the base course. We also chose these values because, as we saw from the results of the laboratory tests, the resilient modulus of the $100 \%$ natural material was actually higher than the $100 \%$ crushed material at stress levels of $200 \mathrm{kPa}$ and less.

The resilient modulus values plotted in Figure 32 were taken at a void ratio of around 0.16 . The results show that it may be possible to use the PI as an indicator of resilient modulus at a bulk stress of $400 \mathrm{kPa}$. At $200 \mathrm{kPa}$, the effect of PI on the resilient modulus was negligible.

A similar attempt was made with the shear property 


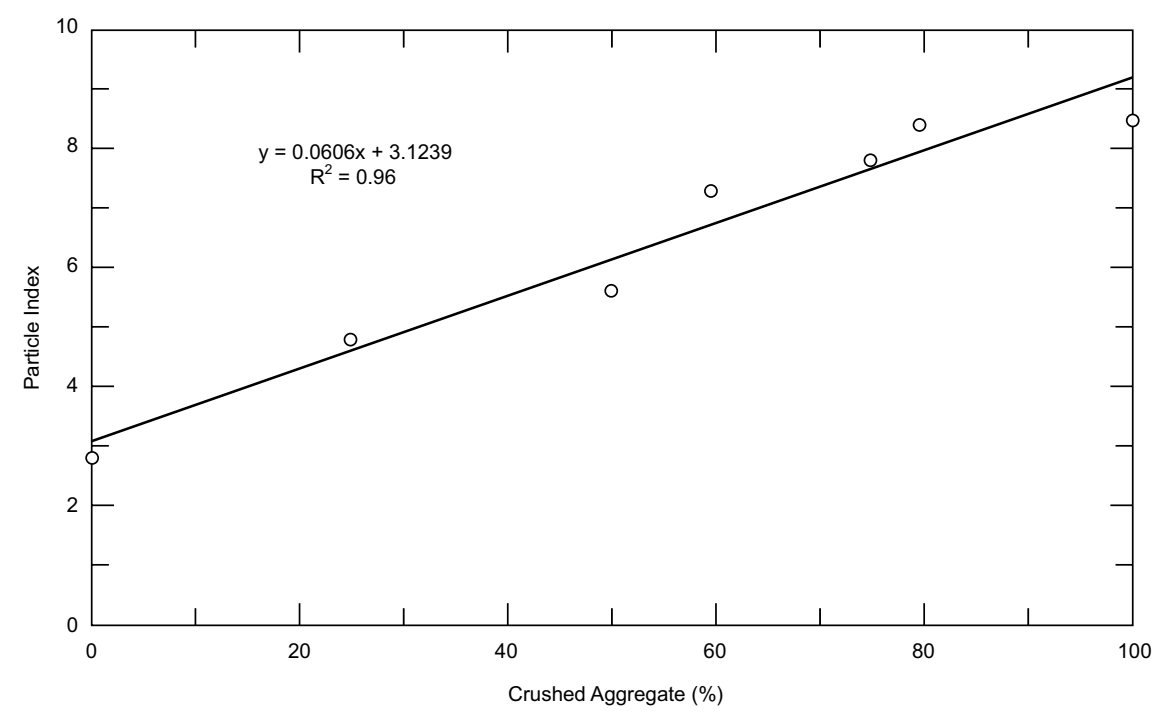

Figure 31. Effect of percentage of crushed aggregate on particle index.

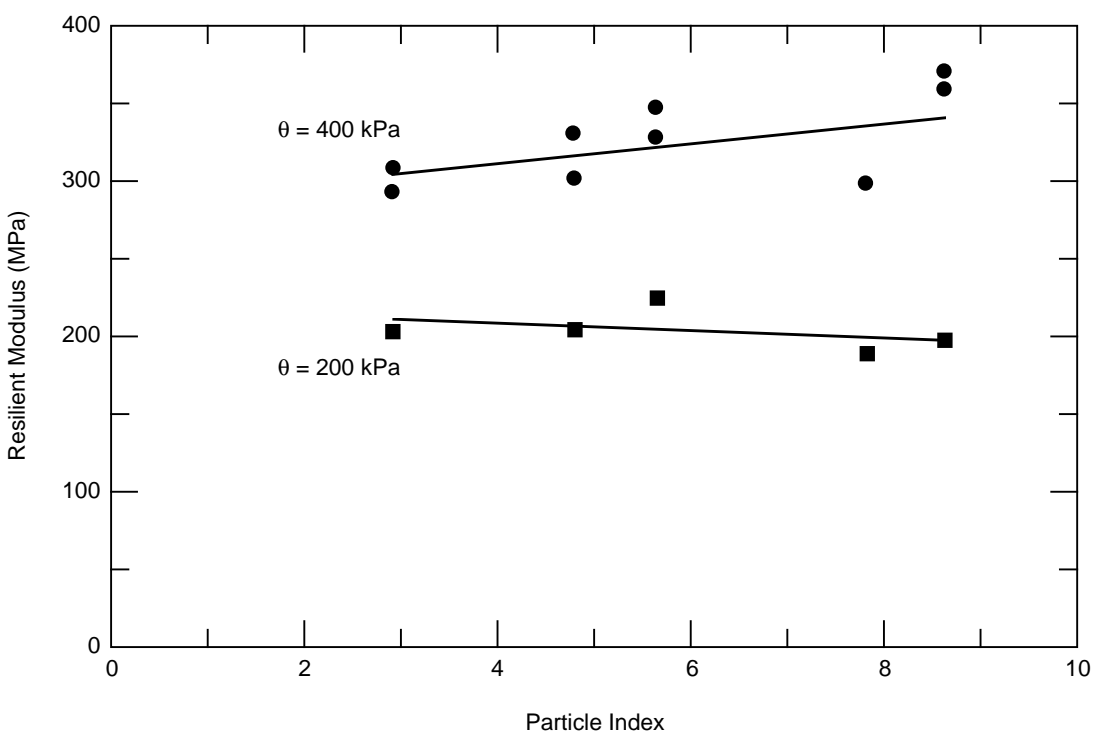

Figure 32. Effect of particle index on resilient modulus.

of the angle of internal friction $(\phi)$ as shown in Figure 33. The limited data were obtained at a void ratio of around 0.16 . Results indicate that there is a trend between $\phi$ and PI and that the $\phi$ angle increases with increasing PI until around 6 , then remains constant.

\section{SUMMARY AND CONCLUSIONS}

On the average, density is about $12 \%$ higher for the large-scale QMOT tests than for the AASHTO T-99 tests. The optimum moisture contents were approximately the same for both tests.

From large-scale resilient modulus tests, results indicate that resilient modulus is a function of the percentage of crushed aggregates and bulk stress. At lower bulk stress values, resilient modulus of the natural aggre- gate mixture is higher than the $100 \%$ crushed aggregate. The trend reverses at bulk stresses greater than $300 \mathrm{kPa}$. This suggests that, at lower depths in a thick base course layer ( $60 \mathrm{~cm}$ or thicker), the lower half of the base course can be constructed with natural material. Results also indicated that void ratio has an impact on the resilient modulus of aggregates containing $50 \%$ or less of crushed aggregates.

With the standard 150-mm-diameter samples, we found that the resilient modulus of the $100 \%$ natural material was higher than that of the $100 \%$ crushed material. Generally, the resilient moduli tended to parallel one another. The resilient modulus was about 35 to $50 \%$ higher than that obtained from the large-scale tests.

From the large-scale shear tests, angle of internal 


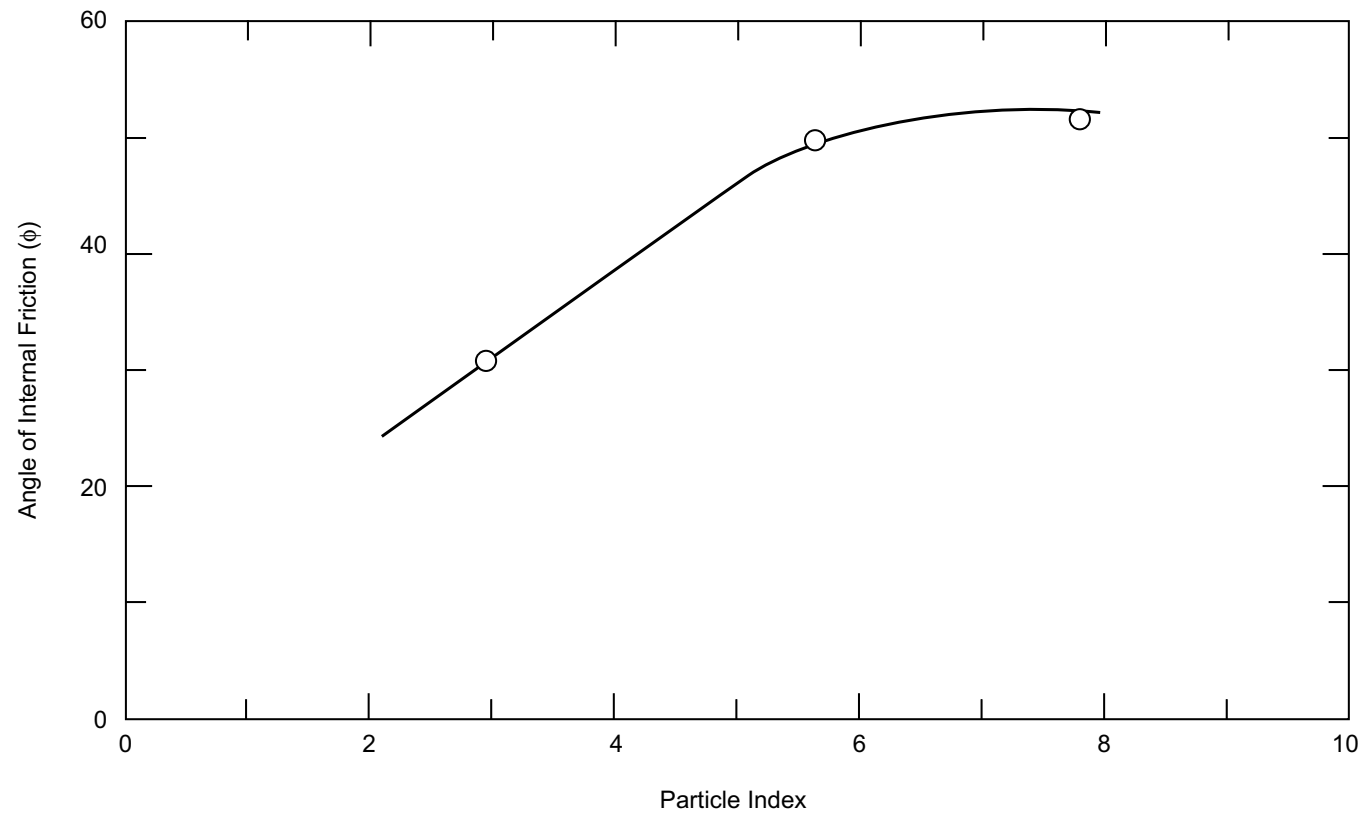

Figure 33. Angle of internal friction as a function of particle index.

frictions ranged between $31^{\circ}$ and $51^{\circ}$. The effect of percent crushed material on the angle of internal friction was minimal at $50 \%$ and higher. However, there was a significant difference when the aggregate was $100 \%$ natural. The difference in the angle of internal friction was $20^{\circ}$. The effect of void ratio was significant on the maximum shear stress and shear strength of the material. There was no distinct effect of confining pressure on the shear strength, except that the shear strength was higher at the higher confining pressure. The effect of void ratio was more significant than that of confining pressure. Similar tests conducted on 150 -mm test samples indicated that the angle of internal friction ranged between 41 and $46^{\circ}$. With these tests, the effect of confining pressure was significant. At $36 \mathrm{kPa}$ confining pressure, the effect of void ratio on shear strength was minimal. However, at $70 \mathrm{kPa}$, void ratio affected the aggregates' shear strength. In both cases, void ratio had a more significant effect on shear strength than did the percentage of crushed aggregates.

The particle index (PI) as modified by Michigan DOT used the complete gradation and was a good indicator of the crushed (angular) content of a given base course gradation. It was found that the PI test can be an indicator of the resilient and shear properties of the base course aggregate gradation.

Results presented in this report are based on test results at optimum densities. The effect of increased moisture content may change the effect of PI on the mechanical properties of base course aggregates.

\section{LITERATURE CITED}

AASHTO TP46-94 (1994) Standard Test Method for Determining the Resilient Modulus of Soils and Aggregate Materials. American Association of State Highway and Transportation Officials Provisional Standard. Allen, J.J., and M.R. Thompson (1974) Resilient response of granular materials subjected to timedependent lateral stresses. Transportation Research Record, 510: 1-13.

ASTM D 2488-90 (1996) Standard practice for description and identification of soils (visual-manual procedure). ASTM, vol. 04.08, Soil and Rock.

Barksdale, R.D., and S.Y. Itani (1994) Influence of aggregate shape on base behavior. Transportation Research Record, 1227: 171-182.

Brown, S.F., and P.S. Pell (1967) An experimental investigation of the stresses, strains and deflections in a layered pavement structure subjected to dynamic loads. In Proceedings of the 2nd International Conference on the Structural Design of Asphalt Pavements, Ann Arbor, Michigan, 7-11 August 1967, p. 487-504. Haynes, J.H., and E.J. Yoder (1963) Effects of repeated loading on gravel and crushed stone base material used in the AASHTO road test. Highway Research Board Record, 39: 82-86.

Hicks, R.G., and C.L. Monismith (1971) Factors influencing the resilient response of granular materials. Highway Research Record, 345: 15-31.

Hicks, R.G., and C.L. Monismith (1972) Prediction of the resilient response of pavements containing granular layers using non-linear elastic theory. In Proceed- 
ings of the 3rd International Conference on the Structural Design of Asphalt Pavements, 11-15 September 1972, London, England, vol. 1, p. 410-429.

Holubec, I., and K.H. Wilson (1970) A cyclic creep study of pavement materials. Final Report, Department of Civil Engineering, University of Waterloo, Ontario, D.H.O. Report No. RR163.

Huang, E.Y. (1965) An improved particle index test for the evaluation of geometric characteristics of aggregate. Michigan Highway Research Project Report No. 86546.

Janoo, V.C. (1997) Evaluation of airport subsurface materials. U.S. Army Cold Regions Research and Engineering Laboratory, Special Report 97-13.

Janoo, V.C. (1998) Quantification of shape, angularity, and surface texture of base course materials. U.S. Army Cold Regions Research and Engineering Laboratory, Special Report 98-1.

Kolisoja, P. (1997) Resilient deformation characteristics of granular materials. Tampere University of Technology, Tampere, Finland, Publication 223.

Lekarp, F. (1999) Resilient and permanent deformation behavior of unbound aggregates under repeated loadings. Royal Institute of Technology, Department of Infrastructure and Planning, Report No. TRITA-IP FR 90-57.

Michigan Transportation Commission (1983) Evaluation of the straight line gradation chart and the particle index test. Research Project 75 E-57, Research Laboratory Section, Testing and Research Division, Lansing, Michigan, Research Report No. R-1210.

Rada, G., and M.W. Witczak (1981) Comprehensive evaluation of laboratory resilient moduli results for granular materials. Transportation Research Record, 810: 23-33.

Sweere, G.T.H. (1990) Unbound granular bases for roads. PhD thesis, Delft University of Technology, Delft, The Netherlands.

Thom, N.H. (1988) Design of road foundations. Ph.D. Thesis, University of Nottingham.

Uzan, J. (1985) Characterization of granular materials. Transportation Research Record, 1022: 52-59.

Yoder, E.J., and M.W. Witczak (1975) Principles of Pavement Design, 2nd edition. New York: John Wiley and Sons, Inc. 
To Contents 


\section{APPENDIX A: RESILIENT MODULUS RESULTS}

(300-mm-diameter specimens)

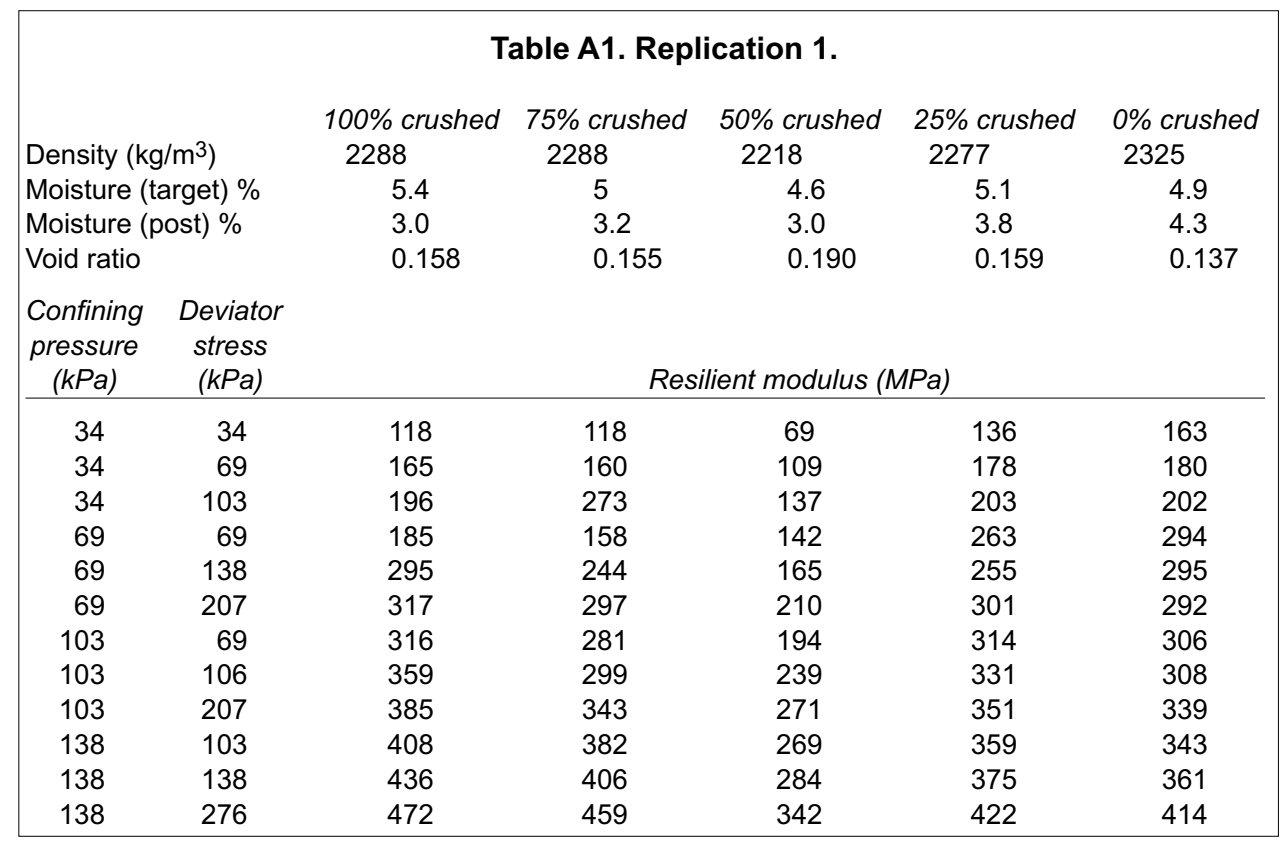

\begin{tabular}{|c|c|c|c|c|c|}
\hline \multicolumn{6}{|c|}{ Table A2. Replication 2.} \\
\hline \multicolumn{2}{|c|}{ Density $\left(\mathrm{kg} / \mathrm{m}^{3}\right)$} & $\begin{array}{l}100 \% \text { crushed } \\
2433\end{array}$ & $\begin{array}{l}75 \% \text { crushed } \\
2288\end{array}$ & $\begin{array}{l}50 \% \text { crushed } 25 \% \text { crushed } \\
2376\end{array}$ & $\begin{array}{l}0 \% \text { crushed } \\
2348\end{array}$ \\
\hline \multicolumn{2}{|c|}{ Moisture (target) \% } & 4.9 & 5 & 4.6 & 4.9 \\
\hline \multirow{2}{*}{\multicolumn{2}{|c|}{$\begin{array}{l}\text { Moisture (post) \% } \\
\text { Void ratio }\end{array}$}} & 1.46 & 2.56 & 4.69 & 4.75 \\
\hline & & 0.089 & 0.158 & 0.1151 & 0.129 \\
\hline \multicolumn{6}{|c|}{$\begin{array}{lc}\text { Confining } & \text { Deviator } \\
\text { pressure } & \text { stress }\end{array}$} \\
\hline 34 & 34 & 168 & 107 & 207 & 219 \\
\hline 34 & 69 & 193 & 153 & 267 & 285 \\
\hline 34 & 103 & 227 & 188 & 311 & 307 \\
\hline 69 & 69 & 265 & 242 & 254 & 401 \\
\hline 69 & 138 & 319 & 364 & 385 & 433 \\
\hline 69 & 207 & 371 & 395 & 484 & 486 \\
\hline 103 & 69 & 293 & 293 & 352 & 497 \\
\hline 103 & 106 & 326 & 346 & 416 & 480 \\
\hline 103 & 207 & 405 & 482 & 532 & 548 \\
\hline 138 & 103 & 355 & 375 & 430 & 747 \\
\hline 138 & 138 & 388 & 420 & 494 & 538 \\
\hline 138 & 276 & 478 & 573 & 625 & 645 \\
\hline
\end{tabular}




\section{APPENDIX B: RESILIENT MODULUS RESULTS (150-mm-diameter specimens)}

\begin{tabular}{|c|c|c|c|c|c|c|c|}
\hline & & & Table B1. & Replication 1. & & & \\
\hline Density & & & $\begin{array}{l}100 \% \text { crushed } \\
2090\end{array}$ & $\begin{array}{l}75 \% \text { crushed } \\
2178\end{array}$ & $\begin{array}{l}50 \% \text { crushed } \\
2174\end{array}$ & $\begin{array}{l}25 \% \text { crushed } \\
2157\end{array}$ & $\begin{array}{l}0 \% \text { crushed } \\
2245\end{array}$ \\
\hline Moisture (ta & yet) $\%$ & & 4.6 & 4.9 & 4.7 & 5.1 & 4 \\
\hline Moisture (p & t) $\%$ & & 3.1 & 2.8 & 3.2 & 3.2 & 3.7 \\
\hline Void ratio & & & 0.268 & 0.217 & 0.219 & 0.267 & 0.180 \\
\hline $\begin{array}{l}\text { Confining } \\
\text { pressure } \\
(\mathrm{kPa})\end{array}$ & $\begin{array}{c}\text { Deviator } \\
\text { stress } \\
(\mathrm{kPa})\end{array}$ & $\begin{array}{c}\text { Bulk } \\
\text { stress } \\
\text { (kPa) }\end{array}$ & $R e$ & lient modulus (I & Pa) & & \\
\hline 21 & 21 & 83 & & & & & \\
\hline 21 & 41 & 103 & 183 & & 197 & 176 & 420 \\
\hline 21 & 62 & 124 & 171 & & 218 & 232 & 253 \\
\hline 34 & 34 & 138 & 247 & & & & \\
\hline 34 & 69 & 172 & 287 & & 333 & 392 & 329 \\
\hline 34 & 103 & 207 & 249 & & 270 & 367 & 277 \\
\hline 69 & 69 & 276 & 420 & & 424 & 427 & \\
\hline 69 & 138 & 345 & 375 & & 410 & 455 & 414 \\
\hline 69 & 207 & 414 & 323 & & 447 & 473 & 392 \\
\hline 103 & 69 & 379 & 430 & & 537 & 103 & \\
\hline 103 & 414 & 390 & 464 & & 510 & 540 & \\
\hline 103 & 207 & 517 & 317 & & 535 & 625 & 521 \\
\hline 138 & 103 & 517 & 440 & & 551 & 798 & 657 \\
\hline 138 & 138 & 552 & 378 & & 624 & 691 & \\
\hline 138 & 276 & 689 & 380 & & 606 & 846 & 575 \\
\hline
\end{tabular}

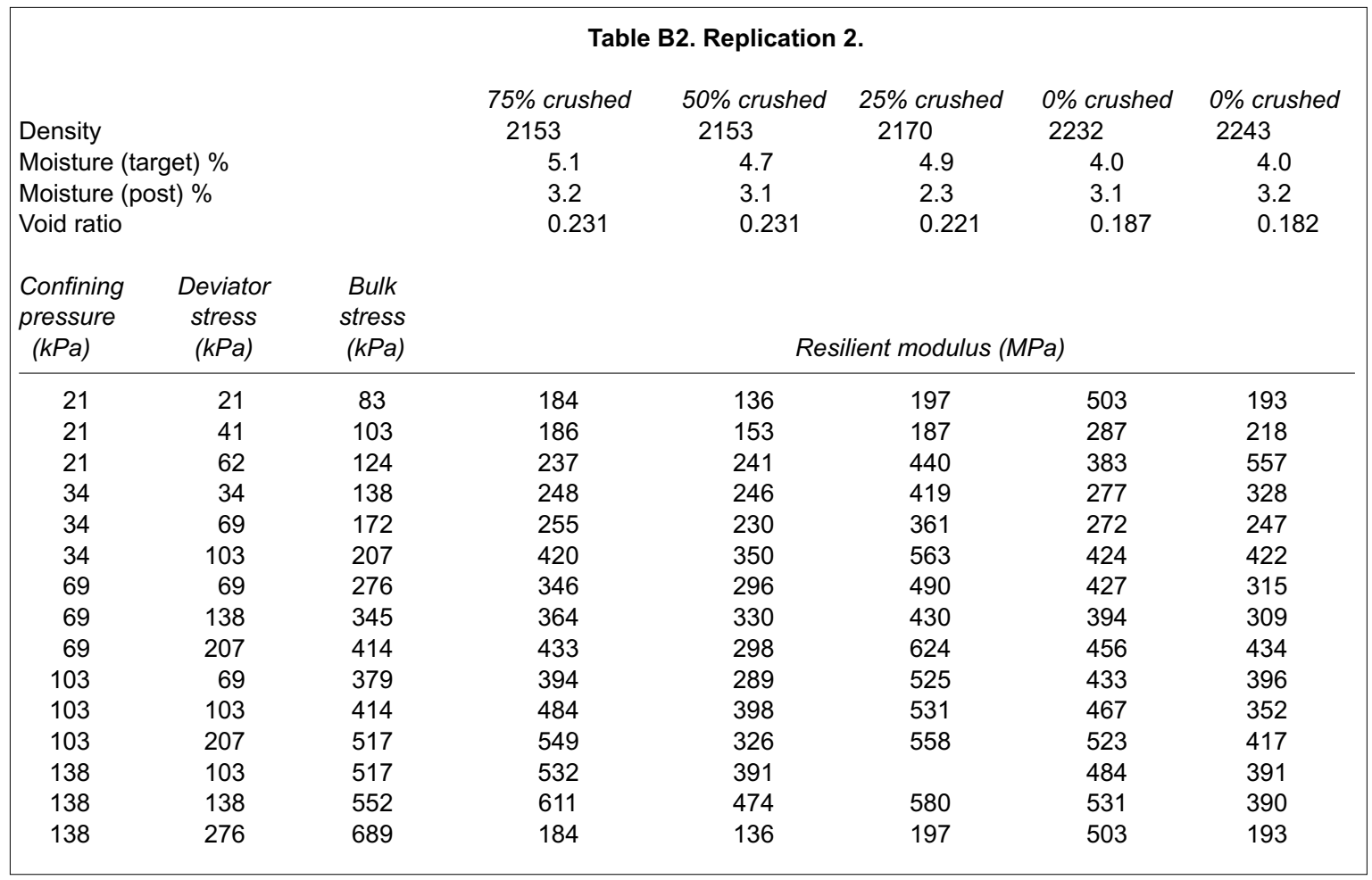




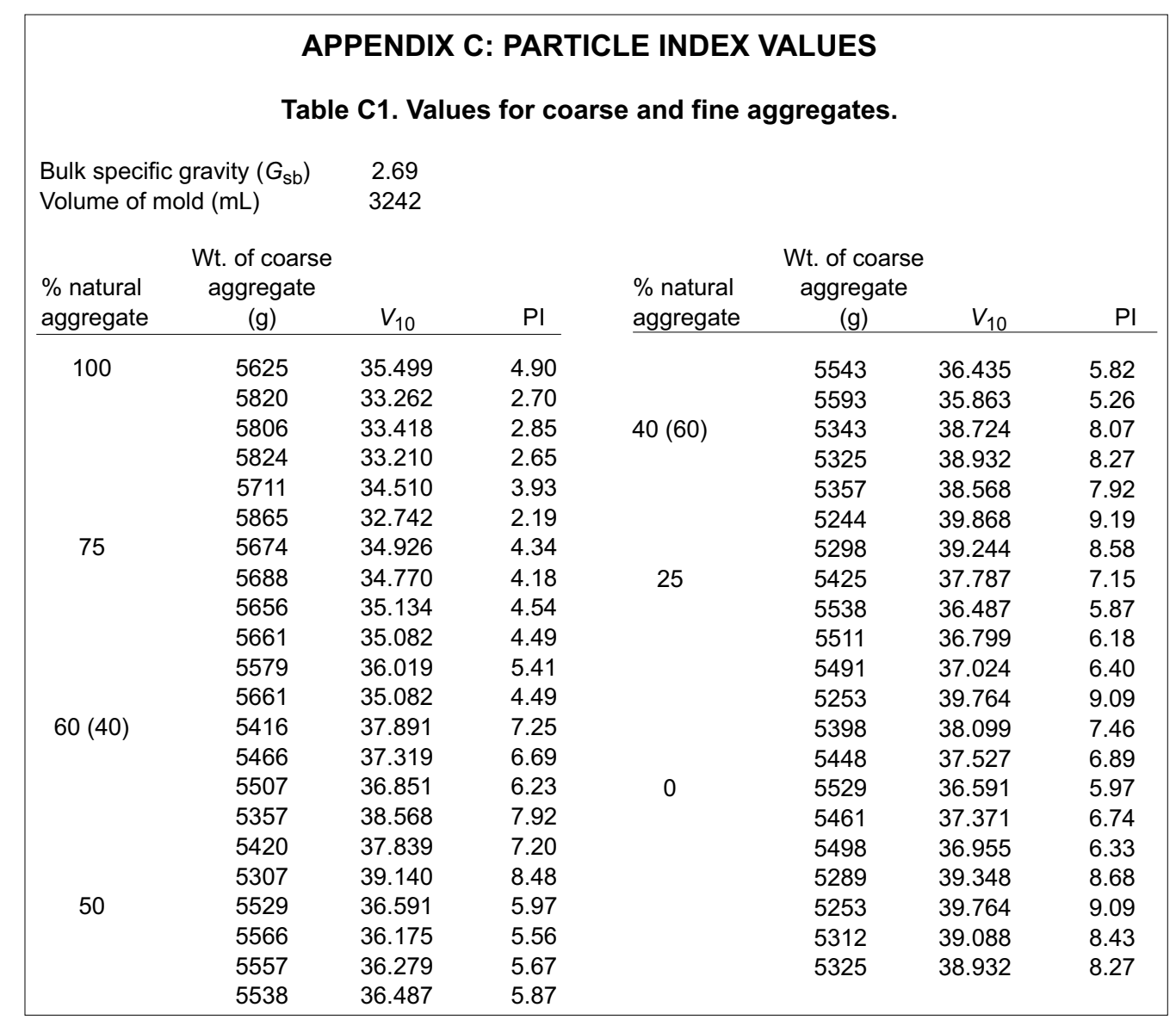




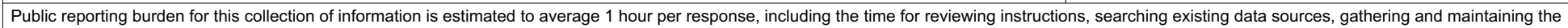

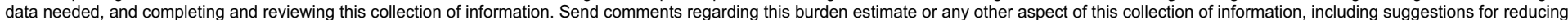

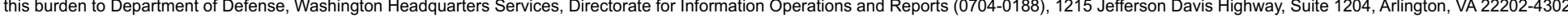

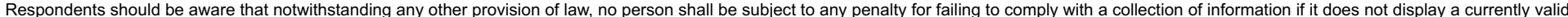
OMB control number. PLEASE DO NOT RETURN YOUR FORM TO THE ABOVE ADDRESS.

\begin{tabular}{|l|l|l|}
\hline 1. REPORT DATE $(D D-M M-Y Y)$ & 2. REPORT TYPE & 3. DATES COVERED (FrOm - TO)
\end{tabular}

September 2001

Technical Report

4. TITLE AND SUBTITLE

5a. CONTRACT NUMBER

5b. GRANT NUMBER

The Effect of Aggregate Angularity on Base Course Performance

5c. PROGRAM ELEMENT NUMBER

6. AUTHOR(S)

5d. PROJECT NUMBER

Vincent C. Janoo and John J. Bayer II

5e. TASK NUMBER

5f. WORK UNIT NUMBER

8. PERFORMING ORGANIZATION REPORT

NUMBER

U.S. Army Engineer Research and Development Center

Cold Regions Research and Engineering Laboratory

72 Lyme Road

ERDC/CRREL TR-01-14

Hanover, New Hampshire 03755-1290

9. SPONSORING/MONITORING AGENCY NAME(S) AND ADDRESS(ES)

10. SPONSOR / MONITOR'S ACRONYM(S)

Vermont Agency of Transportation

National Life Building, Drawer 33

11. SPONSOR / MONITOR'S REPORT

Montpelier, VT 05633-5001

NUMBER(S)

\section{DISTRIBUTION / AVAILABILITY STATEMENT}

Approved for public release; distribution is unlimited.

Available from NTIS, Springfield, Virginia 22161.

13. SUPPLEMENTARY NOTES

\section{ABSTRACT}

The Vermont Agency of Transportation (VAOT) conducted a two-phase study to quantify the resilient modulus and strength characteristics of its subbase material. In Phase 1, a literature review was done to determine the various methods available for indexing the shape, texture, and angularity of coarse aggregates. In the second phase, described in this report, a study was conducted to relate particle index to the mechanical resilient and shear properties of base course materials. The particle index as modified by the Michigan Department of Transportation used the complete gradation and was a good indicator of the crushed (angular) content of a given base course gradation. The particle index test also may be used to indicate resilient and shear properties of base course aggregate gradation.

15. SUBJECT TERMS

$\begin{array}{llll}\text { Aggregates } & \text { Base } & \text { Particle index } & \text { Shear properties } \\ \text { Angularity } & \text { Large-scale samples } & \text { Resilient modulus } & \text { Subbase }\end{array}$

16. SECURITY CLASSIFICATION OF:

\begin{tabular}{|c|c|c|}
\hline a. REPORT & b. ABSTRACT & c. THIS PAGE \\
$\mathrm{U}$ & $\mathrm{U}$ & $\mathrm{U}$ \\
\hline
\end{tabular}

To Contents

\begin{tabular}{|c|c|l|}
$\begin{array}{l}\text { 17. LIMITATION OF } \\
\text { OF ABSTRACT }\end{array}$ & $\begin{array}{l}\text { 18. NUMBER } \\
\text { OF PAGES }\end{array}$ & 19a. NAME OF RESPONSIBLE PERSON \\
\cline { 3 - 3 }$U$ & 35 & 19b. TELEPHONE NUMBER (include area code) \\
$\mathrm{U}$ & & \\
\hline
\end{tabular}

Standard Form 298 (Rev. 8-98) Prescribed by ANSI Std. 239.18 